OPEN ACCESS

Passivity of Holmium Studied Theoretically by Potential-pH Diagrams for Selection of Electrolytes and Experimental Proof of the Formation of Ultra-Thin Anodic Films

To cite this article: Khurram Shahzad et al 2021 J. Electrochem. Soc. 168081509

View the article online for updates and enhancements.

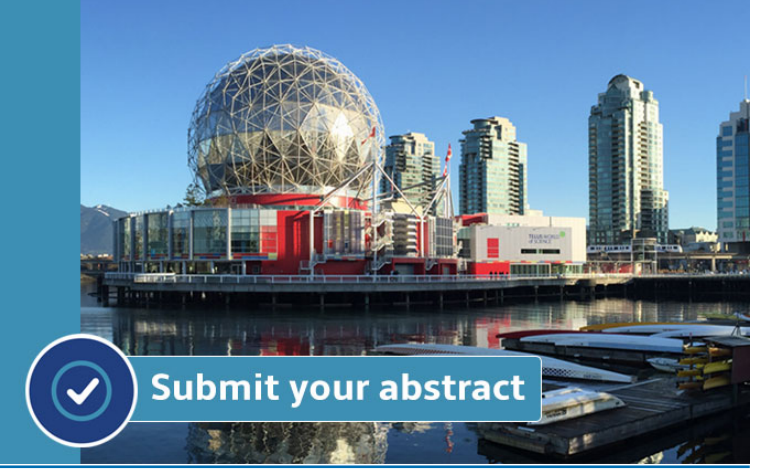




\title{
Passivity of Holmium Studied Theoretically by Potential-pH Diagrams for Selection of Electrolytes and Experimental Proof of the Formation of Ultra-Thin Anodic Films
}

\author{
Khurram Shahzad, ${ }^{1}$ Jan Philipp Kollender, ${ }^{1, *, a}$ (i) Cezarina Cela Mardare, ${ }^{1,2}$ (i) Andrei \\ Ionut Mardare, ${ }^{1}$ (i) and Achim Walter Hassel ${ }^{1,2, *, z}$ (i) \\ ${ }^{1}$ Institute of Chemical Technology of Inorganic Materials, Johannes Kepler University Linz, 4040 Linz, Austria \\ ${ }^{2}$ Christian Doppler Laboratory for Combinatorial Oxide Chemistry (COMBOX) at the Institute for Chemical Technology of \\ Inorganic Materials, Johannes Kepler University Linz, 4040 Linz, Austria
}

\begin{abstract}
We present an efficient strategy to identify anodizing electrolytes by coupling conventional Eh-pH diagrams with first-principles density functional theory calculations. Herein, the growth of ultra-thin films having a thickness of 10-20 nm is successfully demonstrated on thermally evaporated holmium. Considering only thermodynamic basis, simulated Eh-pH diagrams, and solubility analysis, electrolytes having different compositions and $\mathrm{pH}$ values are suggested for the efficient growth of anodic films. The $\mathrm{Eh}-\mathrm{pH}$ diagrams are modified by incorporation of oxide-forming species in such a way to appreciably extend the stability domain. The predicted diagrams showed a strong agreement with the experimental observations and provide a better understanding of $\mathrm{Ho}-\mathrm{H}_{2} \mathrm{O}$ based aqueous systems and can serve as a guide in other rare-earth elements anodizing. Grown film properties are investigated by using electrochemical impedance studies which disclose a linear increase in inverse capacitance with formation voltage indicating a uniform growth of anodic films irrespective of electrolyte selection. Formation factor, $k$, of anodic films grown up to $10 \mathrm{~V}$ varies from 1.16 to $1.95 \mathrm{~nm} V^{-1}$ in selected electrolytes. The $k$ values greater than unity may contribute to the uniform film growth at different $\mathrm{pH}$ values.

(C) 2021 The Author(s). Published on behalf of The Electrochemical Society by IOP Publishing Limited. This is an open access article distributed under the terms of the Creative Commons Attribution Non-Commercial No Derivatives 4.0 License (CC BYNC-ND, http://creativecommons.org/licenses/by-nc-nd/4.0/), which permits non-commercial reuse, distribution, and reproduction in any medium, provided the original work is not changed in any way and is properly cited. For permission for commercial reuse please email: permissions@ioppublishing.org. [DOI: 10.1149/1945-7111/ac120b]
\end{abstract}

Manuscript submitted February 8, 2021; revised manuscript received June 29, 2021. Published August 30, 2021. This paper is part of the JES Focus Issue on Characterization of Corrosion Processes in Honor of Philippe Marcus.

Rare-earth elements (REE's) are becoming increasingly crucial industrial materials, with a unique set of applications in numerous fields such as the medical and nuclear technologies, electronic, magnetic and superconductor industries, as well as for corrosion protection of technologically important metals. ${ }^{1-6}$ REE's are officially referred to as the "lanthanoids," although they are commonly referred to as the "lanthanides." As high-tech industry faces new challenges in the global rare-earth (RE) markets, greater efficiencies in terms of cost-effective production of rare-earth based products will be required. ${ }^{7}$ Industrial applications of REE's can be divided into two categories depending on their uses. One approach involves the use of individual REE's and the other includes REE's mixed with other elements of periodic table in the form of alloys and mixed oxides. The latter approach can be used to boost the properties of individual rare-earth elements and oxides. ${ }^{8-12}$

The RRE's have a large driving force for oxide formation due to their negative equilibrium potential which lies between $-2.52 \mathrm{~V}$ (cerium) and $-2.25 \mathrm{~V}$ (lutetium) vs SHE. These values are similar to magnesium $(-2.37 \mathrm{~V}$ vs SHE) and oxides/hydroxides of RE are generally soluble in acidic solution, while relatively stable in alkaline environments. ${ }^{13,14}$ Despite recent advancement in metal anodizing, only a few efforts have been made to fabricate and understand the electrochemical behavior of oxide films grown by electrochemical oxidation on REE's. ${ }^{15-17}$ One reason is found in the relatively high prices of these elements, making them difficult to be purchased. Therefore, the information's regarding anodic films and resulting film properties are very limited on REE's, despite their high importance in high-tech applications and in the electronics industry.

It is now well established that Pourbaix or Eh-pH diagrams provide comprehensive summaries of stability regions in Metal- $\mathrm{H}_{2} \mathrm{O}$ systems corresponding to metals, oxides, hydroxides, oxyhydroxides,

\footnotetext{
*Electrochemical Society Member.

${ }^{a}$ Present address: Swiss Federal Laboratories for Materials Science and Technology, 8600 Dübendorf, Switzerland.

${ }^{\mathrm{z}}$ E-mail: achimwalter.hassel@jku.at
}

and aqueous ions within the considered ranges of $\mathrm{pH}(-2,16)$ and $\mathrm{V}$ $(-3,3) .{ }^{18}$ Additionally, Eh-pH diagrams have classical use in predicting the stabilities of materials against corrosion in electrochemical catalysis and photocatalysts. ${ }^{19}$ However, major difficulty in predicting the oxidation stability of REE's from Eh-pH is that no attempt has been made to add the thermodynamic information other than RE (rare-earth) hydroxides as reported in pioneering atlas of M. Pourbaix for the $\mathrm{RE}-\mathrm{H}_{2} \mathrm{O}$ systems. ${ }^{13}$ Even for the single metal- $\mathrm{H}_{2} \mathrm{O}$ system, the stability domains of $\mathrm{RE}$ oxides cannot be predicted by simply considering $\mathrm{RE}(\mathrm{OH})_{3}$ data owing to different free energies of formation for metal-oxide and hydroxides. D. G. Brookins explored the stability of REE's in aqueous carbonates system, ${ }^{20,21}$ while K. Eunyoung et al. recently made attempts to simulate some rare-earths Eh- $\mathrm{pH}$ diagrams in the presence of $\mathrm{H}_{2} \mathrm{O}-\mathrm{PO}_{4}{ }^{3-}$ or $\mathrm{H}_{2} \mathrm{O}-\mathrm{SO}_{4}{ }^{3-}$ systems. ${ }^{22} \mathrm{~A}$ crucial missing piece in the existing publications is that none of them consider the electrolyte compositions directly relevant to metal anodizing such as borate, phosphate, citrate, oxalate, malonate, tartrate, and acetate, thereby theoretical prediction of REE anodizing in a given electrolyte is ambiguous. The electrochemical behavior of a metal depends on the electrolyte composition which is in contact with the immersed metal. When a metallic system forms soluble complexes of different stability with other substances (such as citrate, phosphate, and borate), the Eh-pH diagrams for the metal- $\mathrm{H}_{2} \mathrm{O}$ system must be modified. It is expected that addition of various substances may modify the thermodynamic stability domains as well as the domains of relative predominance of the dissolved species. In order to accurately predict the realistic equilibrium relationships among solid and dissolved species in a system under consideration, it is critical to have reliable thermodynamic data for the relevant species. Compared with single metal- $\mathrm{H}_{2} \mathrm{O}$ system, the inclusion of additional species encounters the obstacle of getting thermodynamic information of species and phases of interest and retrieving from numerous publications, the thermodynamic data of various species covering the entire $\mathrm{pH}$ range for oxidation of metals and alloys is a very challenging task. Although there are a large number of thermodynamic reports for rareearth oxides, phosphates, and citrates species, the reported values may differ widely for the same species. Thereby, finding an electrolyte suitable for growing stable anodic films on REE's is in itself a very 
tedious task and requires many attempts to produce a film with desired properties required for practical applications. To minimize the number of experimental efforts, Eh- $\mathrm{pH}$ and solubility diagrams of Ho metal are simulated in the presence of various oxide-forming substances in order to predict the thermodynamic stability of anodic films formed on Ho.

Therefore, the aim of this paper is to provide the thermodynamic basis for the electrochemical fabrication of ultra-thin films on rarely explored Ho metal in different electrolytes containing oxide-forming substances. One reason for Ho selection in the present study was the recent scientific attention for huge data storage at atomic scale by IBM group ${ }^{8,23}$ and its unprecedented highest magnetic permeability. ${ }^{24}$ The importance of Ho and its oxide is well discussed in a separate investigation. ${ }^{25}$ Another objective of the study is to provide a reliable summary of the electrochemical behavior for Ho in selected electrolyte having different $\mathrm{pH}$ ranges (citrate, borate, and phosphate) to electrochemists, physicists, chemical engineers, and metallurgists, based on collection of thermodynamic data. Such information's may also become the basis for anodizing and expansion of application window for other REE's as well owing to the fact that REE's often possess similar trends with respect to many chemical properties.

\section{Experimental}

High purity Ho $(99.99 \%$, Smart Elements) thin films were deposited on borosilicate glass substrates (VWR International $\mathrm{GmbH}$ ) having dimensions of $26 \times 76 \mathrm{~mm}^{2}$. This was done by employing a self-developed thermal evaporator with a base pressure of $10^{-5} \mathrm{~Pa}$. Prior to deposition the substrates were cleaned by ultrasonication in acetone, isopropanol, and water followed by drying under $\mathrm{N}_{2}$ flow. Ho fragments/pellets were placed in a commercial W thermal boat (Kurt J. Lesker) able to sink DC currents up to $300 \mathrm{~A}$. An external power source ( $3.5 \mathrm{~kW} \mathrm{DC)} \mathrm{applied}$ $250 \mathrm{~W}$ on the thermal element for reaching the Ho evaporation temperature of $770{ }^{\circ} \mathrm{C}$. A deposition rate of $0.3 \mathrm{~nm} \mathrm{~s}^{-1}$ was measured in situ by a quartz crystal microbalance (QCM-Inficon) positioned directly above the evaporation source. The deposition distance was $120 \mathrm{~mm}$ and the evaporation was stopped as soon as a total thickness of $400 \mathrm{~nm}$ was measured by the QCM.

The crystal structure of evaporated Ho films was identified by $\mathrm{x}$-ray diffraction (XRD) working in a $\theta-2 \theta$ (Bragg-Brentano) geometry employing $\mathrm{CuK} \alpha$ radiation (Philips X'Pert Pro), while the surface morphologies of as-evaporated and as-anodized thin films were examined using scanning electron microscopy (SEM-FEI Philips XL30 ESEM FEG). Electrochemical studies on Ho thin films were performed using a self-developed three-electrode scanning droplet cell microscopy (SDCM) system. The SDCM body contains a platinum wire as counter electrode wrapped around a glass capillary, and $\mathrm{Ag} / \mathrm{AgCl} \mu$-reference electrode and results are converted to SHE to allow a direct comparison. The metallic thin film deposited on glass was used as working electrode. Potentiodynamic anodizing was performed at different sweep rates of $10,50,100,200,500$, and $1000 \mathrm{mV} \mathrm{s}^{-1}$ in selected electrolytes of varying $\mathrm{pH}$. The anodic polarization potential was stepwise increased with $1 \mathrm{~V}$ steps up to a maximum of $10 \mathrm{~V}$ vs SHE. The

Table I. Literature survey of chemical and electrochemical reactions and standard Gibbs free energy of formation for selected systems.

\begin{tabular}{|c|c|c|c|}
\hline Chemical and electrochemical reactions & $\Delta G_{\mathbf{R}}^{o}\left(\mathrm{~kJ} \mathrm{~mol}^{-1}\right)$ & Species & $\Delta G_{\mathrm{f}}^{o}\left(\mathrm{~kJ} \mathrm{~mol}^{-1}\right)$ \\
\hline \multicolumn{4}{|l|}{$\mathrm{H}_{2} \mathrm{O}$} \\
\hline $2 \mathrm{H}_{2} \mathrm{O}(\mathrm{l}) \rightarrow 4 \mathrm{H}^{+}+4 \mathrm{e}^{-}+\mathrm{O}_{2}(\mathrm{~g})$ & 474.27 & $\mathrm{H}_{2} \mathrm{O}$ & -237.370 \\
\hline \multicolumn{4}{|l|}{$\mathrm{Ho}-\mathrm{H}_{2} \mathrm{O}$ system } \\
\hline $\mathrm{Ho}^{3+}+3 \mathrm{e}^{-} \rightarrow \mathrm{Ho}$ & 674.2 & $\mathrm{Ho}^{3+}$ & -674.200 \\
\hline $\mathrm{Ho}^{3+}+3 \mathrm{H}_{2} \mathrm{O} \rightarrow 3 \mathrm{H}^{+}+\mathrm{Ho}(\mathrm{OH})_{3}(\mathrm{~s})$ & 87.87 & $\mathrm{Ho}(\mathrm{OH})_{3}(\mathrm{~s})$ & -1298.44 \\
\hline $\mathrm{Ho}^{3+}+4 \mathrm{H}_{2} \mathrm{O} \rightarrow 4 \mathrm{H}^{+}+\mathrm{Ho}(\mathrm{OH})_{4}^{-}$ & 191.3 & $\mathrm{Ho}(\mathrm{OH})_{4}^{-}$ & -1432.36 \\
\hline $2 \mathrm{Ho}^{3+}+3 \mathrm{H}_{2} \mathrm{O} \rightarrow \mathrm{Ho}_{2} \mathrm{O}_{3}+6 \mathrm{H}^{+}$ & 268.91 & $\mathrm{Ho}_{2} \mathrm{O}_{3}$ & -1791.60 \\
\hline $2 \mathrm{Ho}+3 \mathrm{H}_{2} \mathrm{O} \rightarrow \mathrm{Ho}_{2} \mathrm{O}_{3}+6 \mathrm{H}^{+}+6 \mathrm{e}^{-}$ & -1091.49 & & \\
\hline \multicolumn{4}{|l|}{$\begin{array}{l}\mathrm{Ho}-\mathrm{H}_{2} \mathrm{O}-0.1 \mathrm{M} \mathrm{cit}^{3-}-0.2 \mathrm{M} \mathrm{PO}_{4}{ }^{3-} \\
\text { system }\end{array}$} \\
\hline $\mathrm{cit}^{3-}+\mathrm{Ho}^{3+} \rightarrow \mathrm{Ho}(\mathrm{cit})$ (aq.) & -53.54 & $\mathrm{Ho}(\mathrm{cit})$ & -1889.58 \\
\hline $2 \mathrm{H}^{+}+\mathrm{Ho}^{3+}+\mathrm{PO}_{4}^{3-} \rightarrow \mathrm{HoH}_{2} \mathrm{PO}_{4}^{2+}$ & -127.55 & $\mathrm{HoH}_{2} \mathrm{PO}_{4}{ }^{2+}$ & -1826.50 \\
\hline $2 \mathrm{PO}_{3}^{2-}+\mathrm{Ho}^{3+} \rightarrow \mathrm{Ho}\left(\mathrm{PO}_{4}\right)_{2}^{3-}$ & -121.53 & $\mathrm{Ho}(\mathrm{PO} 4)_{2}^{3-}$ & -2845.20 \\
\hline $\mathrm{Ho}^{3+}+\mathrm{PO}_{4}^{3-} \rightarrow \mathrm{HoPO}_{4}(\mathrm{~s})$ & -143.04 & $\mathrm{HoPO}_{4}(\mathrm{~s})$ & -1835.04 \\
\hline \multicolumn{4}{|l|}{$\mathrm{Ho}-\mathrm{H}_{2} \mathrm{O}-0.2 \mathrm{M} \mathrm{PO}_{4}{ }^{3-}$ system } \\
\hline $\mathrm{Ho}^{3+}+2 \mathrm{PO}_{4}^{3-} \rightarrow \mathrm{Ho}\left(\mathrm{PO}_{4}\right)_{2}^{3-}$ & -121.53 & & \\
\hline $2 \mathrm{H}^{+}+\mathrm{Ho}^{3+}+\mathrm{PO}_{4}^{3-} \rightarrow \mathrm{HoH}_{2} \mathrm{PO}_{4}^{2+}$ & -127.53 & & \\
\hline $\mathrm{Ho}^{3+}+\mathrm{PO}_{4}^{3-} \rightarrow \mathrm{HoPO}_{4}(\mathrm{~s})$ & -143.04 & & \\
\hline \multicolumn{4}{|l|}{ B- $\mathrm{H}_{2} \mathrm{O}$ system } \\
\hline $2 \mathrm{~B}(\mathrm{OH})_{3} \rightarrow \mathrm{B}_{2} \mathrm{O}_{3}(\mathrm{cr})+3 \mathrm{H}_{2} \mathrm{O}$ & 32.78 & $\mathrm{~B}_{2} \mathrm{O}_{3}(\mathrm{cr})$ & -1194.79 \\
\hline $\mathrm{H}_{3} \mathrm{BO}_{3}(\mathrm{~s}) \rightarrow \mathrm{B}(\mathrm{OH})_{3}$ & 0.40 & $\mathrm{H}_{3} \mathrm{BO}_{3}(\mathrm{~s})$ & -969.440 \\
\hline $\mathrm{B}(\mathrm{cr})+3 \mathrm{H}_{2} \mathrm{O} \rightarrow 3 \mathrm{H}^{+}+3 \mathrm{e}^{-}+\mathrm{B}(\mathrm{OH})_{3}$ & -257.73 & $\mathrm{~B}(\mathrm{OH})_{3}$ & -969.840 \\
\hline $3 \mathrm{~B}(\mathrm{OH})_{3} \rightarrow \mathrm{H}^{+}+\mathrm{B}_{3} \mathrm{O}_{3}(\mathrm{OH})_{4}^{-}$ & 40.112 & $\mathrm{~B}_{3} \mathrm{O}_{3}(\mathrm{OH})_{4}^{-}$ & -2869.40 \\
\hline \multirow{2}{*}{\multicolumn{3}{|c|}{$\begin{array}{l}2 \mathrm{Ho}+2 \mathrm{~B}+3 \mathrm{O}_{2} \rightarrow 2 \mathrm{HoBO}_{3} \\
\text { cit }^{\mathbf{3}-}-\mathbf{H}_{\mathbf{2}} \mathbf{O} \text { system }\end{array}$}} & -1727.00 \\
\hline & & & -116180 \\
\hline $\mathrm{H}^{+}+\mathrm{cit}^{3-} \rightarrow \mathrm{H}(\mathrm{cit})^{2-}$ & -36.50 & $\mathrm{H}(\mathrm{cit})^{2-}$ & -1101.80 \\
\hline $2 \mathrm{H}^{+}+\mathrm{cit}^{3-} \rightarrow \mathrm{H}_{2}(\mathrm{cit})^{-}$ & -63.66 & $\mathrm{H}_{2}$ (cit) & -1225.46 \\
\hline $3 \mathrm{H}^{+}+\mathrm{cit}^{3-} \rightarrow \mathrm{H}_{3}$ (cit) & -81.51 & $\mathrm{H}_{3}$ (cit) & -1243.31 \\
\hline \multicolumn{4}{|l|}{$\mathrm{P}-\mathrm{H}_{2} \mathrm{O}$ system } \\
\hline $\mathrm{P}(\mathrm{cr})+4 \mathrm{H}_{2} \mathrm{O} \rightarrow 8 \mathrm{H}^{+}+5 \mathrm{e}^{-}+\mathrm{PO}_{4}{ }^{3-}$ & -75.26 & $\mathrm{PO}_{4}{ }^{3-}$ & -1024.74 \\
\hline $\mathrm{H}^{+}+\mathrm{PO}_{4}^{3-} \rightarrow \mathrm{HPO}_{4}{ }^{2-}$ & -70.44 & $\mathrm{HPO}_{4}{ }^{2-}$ & -509.020 \\
\hline $2 \mathrm{H}^{+}+\mathrm{PO}_{4}^{3-} \rightarrow \mathrm{H}_{2} \mathrm{PO}_{4}^{2-}$ & -111.57 & $\mathrm{H}_{2} \mathrm{PO}_{4}^{2-}$ & -550.180 \\
\hline $3 \mathrm{H}^{+}+\mathrm{PO}_{4}{ }^{3-} \rightarrow \mathrm{H}_{3} \mathrm{PO}_{4}$ & -123.83 & $\mathrm{H}_{3} \mathrm{PO}_{4}$ & -562.360 \\
\hline
\end{tabular}


addressed area $\left(0.0490 \mathrm{~cm}^{2}\right)$ during the use of the droplet cell was measured by examining the scanning electron microscopy image of an oxide spot formed on Ho. Evaluation of the oxide film thickness and capacitance was performed by in situ electrochemical impedance spectroscopy (EIS) using a CompactStat electrochemical interface system (IVIUM Technologies, The Netherlands) combined with an integrated frequency response analyzer. After each step of potential increase, simultaneous EIS measurements were performed with an AC amplitude of $50 \mathrm{mV}$ in a frequency range of $10^{5}-10^{-1} \mathrm{~Hz}$. The frequency range is selected in such a way to avoid chemical dissolution of growing anodic film during EIS frequency scans. Eh-pH and solubility diagrams data were taken using Medusa and Geochemist's workbench software's (see Table I). For accurate prediction of solid-aqueous reaction energies, recently proposed first-principles calculations by K.A Persson et al. were also used to compute phase diagrams and Pourbaix diagrams with the aid of Python programming and Pymatgen module. ${ }^{26,27}$ Information's regarding formation energies of species were also taken from opensource web application. ${ }^{28}$

\section{Results and Discussion}

Eh-pH diagrams with respect to many environmental parameters such as electrolyte $\mathrm{pH}$, aqueous ion concentration, electrode potential, dissolved gasses, complex agents, ligands formations, and temperature can be used to understand and predict reduction, oxidation, and dissolution trends of materials stability. ${ }^{13}$ Additionally, robust passive oxide films must possess a wide range of thermodynamic stability in a variety of harsh environments and starting point is usually expressed in terms of electrochemical Eh-pH stability diagrams. Therefore, let us first consider the equilibrium between $\mathrm{Ho}-\mathrm{H}_{2} \mathrm{O}$ system as the simplest case.

$\boldsymbol{H o}-\mathrm{H}_{2} \mathrm{O}$ system.-Figures $1 \mathrm{a}, 1 \mathrm{~b}$ shows the Eh-pH diagrams for the $\mathrm{Ho}-\mathrm{H}_{2} \mathrm{O}$ system at three different concentrations for hydroxide/ oxide formation in the absence of any other substance with which Ho metal can form soluble/insoluble salts or complexes. Due to large variation in free energies $\left(\Delta \mathrm{G}_{\mathrm{f}}^{\mathrm{o}}\right.$ for $\mathrm{Ho}(\mathrm{OH})_{3}=-1298.4 \mathrm{~kJ} \mathrm{~mol}^{-1}$ and $\Delta \mathrm{G}_{\mathrm{f}}^{\mathrm{o}}$ for $\mathrm{Ho}_{2} \mathrm{O}_{3}=-1791.6 \mathrm{~kJ} \mathrm{~mol}^{-1}$ ), oxide and hydroxide formation occur at different $\mathrm{pH}$ range. The relatively negative potential of Ho $(-2.33 \mathrm{~V}$ vs SHE), indicates that its domain of stability lies well below the $\mathrm{H}_{2} \mathrm{O} \cdot{ }^{13,14}$ Therefore, Ho is highly unstable in the presence of aqueous electrolytes $\left(\Delta \mathrm{G}_{\mathrm{f}}^{\mathrm{o}}\right.$ for $\mathrm{Ho}^{3+}=$ $-674.2 \mathrm{~kJ} \mathrm{~mol}^{-1}$ ) and it generally oxidizes to $\mathrm{Ho}^{3+}$ and forms oxides/hydroxides in alkaline electrolytes as can be seen in Figs. 1a, 1b. Furthermore, it can be observed that the stability range of both oxide/hydroxide shrinks with reducing concentration of dissolved Ho. This suggests that the oxidation window for anodizing depends on the concentration of dissolved metal species and thereby, higher concentration of dissolved Ho provides a wider $\mathrm{pH}$ range (from 5.15 to 14 at $1 \mathrm{M}$ in the case of $\mathrm{Ho}(\mathrm{OH})_{3}$ formation) for anodic oxidation as compared with the low concentration of dissolved Ho (stability range from 7.2 to 12.1 at $1 \mu \mathrm{M}$ ).

The instability of Ho is also justified by the negative free energy formation values of $\mathrm{Ho}^{3+}, \mathrm{Ho}(\mathrm{OH})_{3}, \mathrm{Ho}_{2} \mathrm{O}_{3}, \mathrm{Ho}(\mathrm{OH})_{4}{ }^{-}$in aqueous electrolyte (Table I). The Gibbs free energies of each reactions, $\Delta \mathrm{G}_{\mathrm{R}}^{\mathrm{o}}$ and species, $\Delta \mathrm{G}_{\mathrm{f}}^{\mathrm{o}}$ are calculated from the equilibrium constant $\mathrm{K}$ (non-redox reactions) and $E^{o}$ values (redox reactions) by considering the following equations:

$$
\begin{gathered}
\log \mathrm{K}=\frac{-\Delta G^{o}}{R T} \\
E^{o}=\frac{-\Delta G^{o}}{-96.49 \mathrm{n}}
\end{gathered}
$$

in which $\mathrm{R}$ is the gas constant $\left(8.314 \mathrm{~J} \mathrm{~mol}^{-1} \mathrm{~K}^{-1}\right), \mathrm{T}$ is the temperature in $\mathrm{K}$ and $\mathrm{n}$ represents the number of electrons in an equation. As an example of a method of calculation of the Eh-pH diagrams from Medusa and Geochemist workbench software's, lets us consider the formation of $\mathrm{Ho}(\mathrm{OH})_{3}$ from $\mathrm{H}_{2} \mathrm{O}$ and $\mathrm{Ho}^{3+}$ :

$$
\mathrm{Ho}^{3+}+3 \mathrm{H}_{2} \mathrm{O} \rightarrow 3 \mathrm{H}^{+}+\mathrm{Ho}(\mathrm{OH})_{3}(\mathrm{~s}) \log \mathrm{K}=-15.4
$$

The Gibbs free energy of this reaction $\left(\Delta \mathrm{G}_{\mathrm{R}}^{\mathrm{O}}=87.87 \mathrm{~kJ} \mathrm{~mol}^{-1}\right)$ is obtained by using the Eq. 1a. Similarly, the $\Delta \mathrm{G}_{\mathrm{f}}^{\mathrm{o}}$ for $\mathrm{Ho}(\mathrm{OH})_{3}$ can be calculated from $\Delta G_{f}^{o}$ values for $\mathrm{Ho}^{3+}, \mathrm{H}_{2} \mathrm{O}$ and $\Delta G_{R}^{o}$.

The effect of various oxide-forming substances such as borate, phosphate, and citrate on equilibrium $\mathrm{Eh}-\mathrm{pH}$ diagrams of a $\mathrm{Ho}-\mathrm{H}_{2} \mathrm{O}$ system during anodizing can be predicted by using two different approaches. In the first approach, superimposition of Eh-pH diagrams of the $\mathrm{Ho}-\mathrm{H}_{2} \mathrm{O}$ system with borate, phosphate, and citrate can provide an initial guess for the regions of stability. However, this
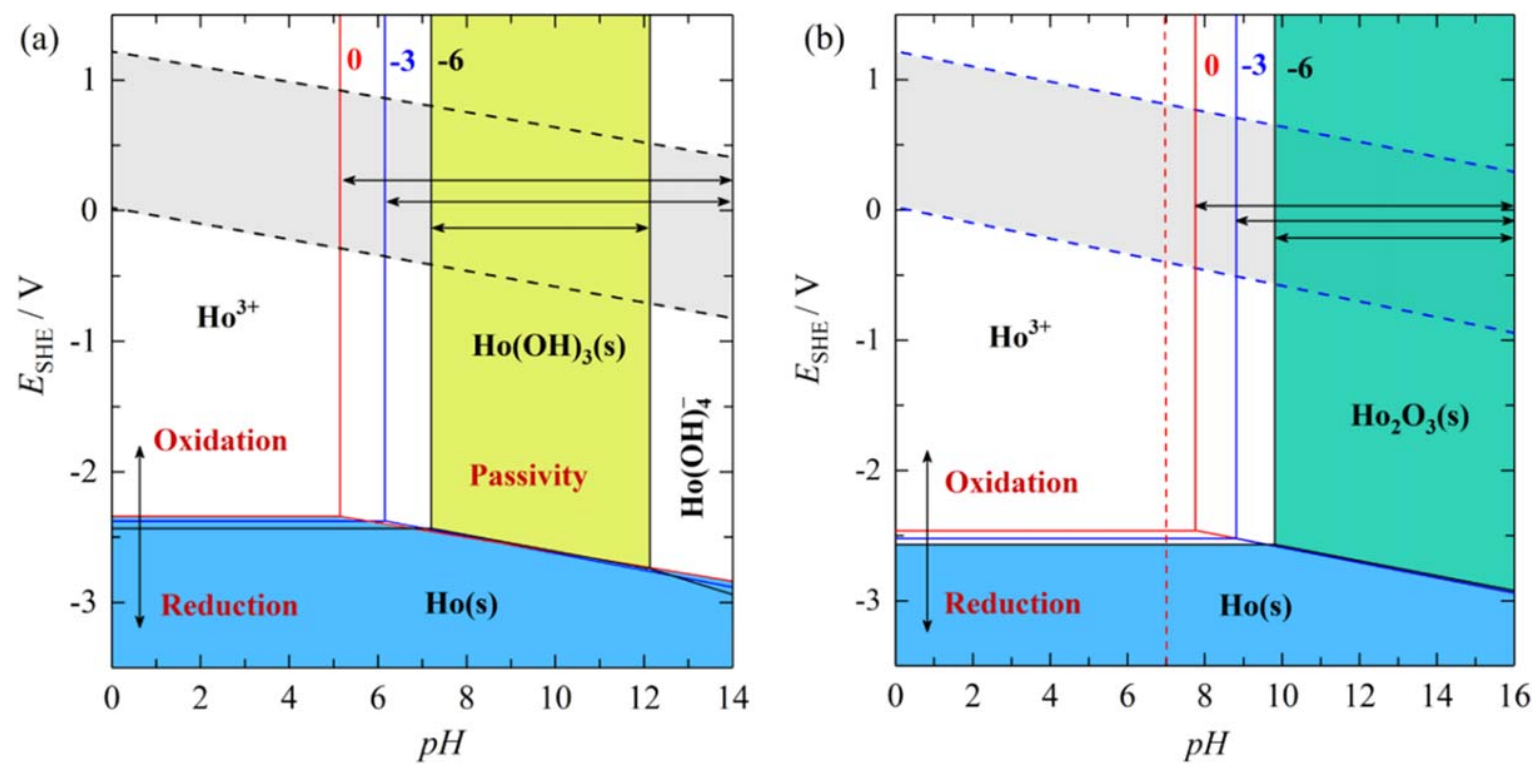

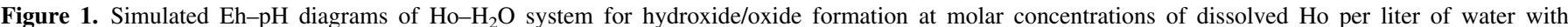

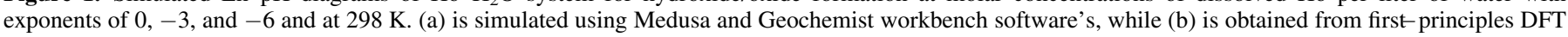
method. 
approach does not incorporate the actual equilibrium reactions of the metal- $\mathrm{H}_{2} \mathrm{O}$ system in the presence of the aforementioned substances.

Nevertheless, construction of Eh- $\mathrm{pH}$ diagrams by considering Gibbs free energies and solubility data in complex-forming substances may provide a more accurate prediction prior to anodizing. Therefore, in the present investigation, we studied these equilibrium diagrams of $\mathrm{Ho}-\mathrm{H}_{2} \mathrm{O}$ for hydroxide formation in these substances with the aid of both approaches. Furthermore, before constructing the actual Eh-pH diagrams, it is also necessary to simultaneously look at the stability fields of citrate $\left(\mathrm{cit}^{3-}\right)$, phosphate $\left(\mathrm{PO}_{4}{ }^{3-}\right)$, and borates $\left(\mathrm{B}(\mathrm{OH})_{4}{ }^{-}\right)$in aqueous solution for better understanding (Fig. 2). For simplification, immune or passive regions at $10^{-6}$ concentration, where growth of Ho can be possible at high Faradaic efficiency is represented by filled colors in Fig. 3.

Ho- $\mathrm{H}_{2} \mathrm{O}$-borate system.-As it is directly observable (Fig. 2c), the stability of orthoboric acid $\mathrm{H}_{3} \mathrm{BO}_{3}$, is largely dependent on $\mathrm{pH}$ of the electrolyte. The solubility of $\mathrm{H}_{3} \mathrm{BO}_{3}$ and $\mathrm{B}(\mathrm{OH})_{3}$ increases with the increase in the $\mathrm{pH}$ of the electrolyte, leading to the formation of soluble complexes such as $\mathrm{B}_{3} \mathrm{O}_{3}(\mathrm{OH})_{4}{ }^{-}$in the $\mathrm{Ho}(\mathrm{OH})_{3}$ stability field. Careful examination of Gibbs free energy data (Table I)

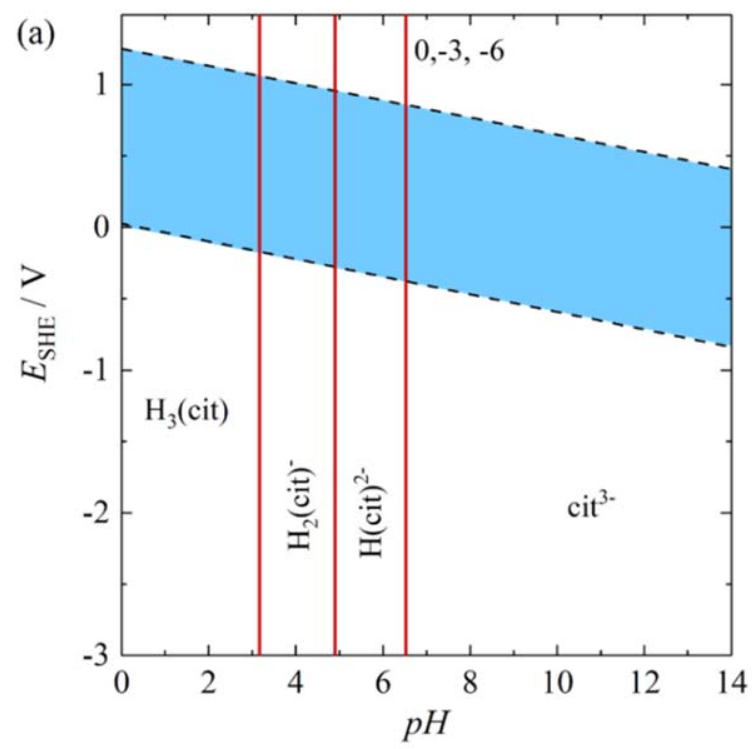

reveals that hydroxides/oxides of Ho are relatively more stable as compared with $\mathrm{B}(\mathrm{OH})_{3} / \mathrm{B}_{2} \mathrm{O}_{3}$. Hence, it is likely that electrolytes containing either borate or ammonium pentaborate do not affect the stability domain of $\mathrm{Ho}(\mathrm{OH})_{3}$ as it can be seen from the $\mathrm{Ho}-\mathrm{H}_{2} \mathrm{O}$ system by the addition of $\mathrm{B}(\mathrm{OH})_{3}$ in Fig. 3a. Therefore, electrolytes containing either borate buffer $(\mathrm{pH} 9.0)$ or ammonium pentaborate tetrahydrate $(\mathrm{pH}$ 7.6) can be treated in a similar way from thermodynamic viewpoint for predicting the oxidation stability of Ho. Though, we must keep in mind that, the formation of soluble complexes of various nature in the presence of orthoboric acid and ammonium pentaborate may significantly influence the electrolyte $\mathrm{pH}$ as well as the kinetics of the electrochemical system.

Ho- $\mathrm{H}_{2} \mathrm{O}$-citrate system.- In contrast to the $\mathrm{B}(\mathrm{OH})_{3}{ }^{-} \mathrm{H}_{2} \mathrm{O}$ system, citrate- $\mathrm{H}_{2} \mathrm{O}$ system behaves in a completely different manner. Citrate ions $\left(\mathrm{cit}^{3-}\right)$ occupy the entire potential-pH field above $6.5 \mathrm{pH}$ (Fig. 2a) and form soluble complexes such as $\mathrm{H}$ (cit) ${ }^{-}$, $\mathrm{H}(\mathrm{cit})^{2-}$ below $\mathrm{pH}$ 6.5. Furthermore, citrate ions form aqueous Ho (cit) with negative Gibbs free energy of formation $\left(\Delta \mathrm{G}_{\mathrm{f}}^{\mathrm{o}}=\right.$ $-1890 \mathrm{~kJ} \mathrm{~mol}^{-1}$ ) compared with $\mathrm{Ho}(\mathrm{OH})_{3} / \mathrm{Ho}_{2} \mathrm{O}_{3}$ (Table I). For this reason, Eh-pH diagram of $\mathrm{Ho}-\mathrm{H}_{2} \mathrm{O}-$ citrate system (Fig. 3b)

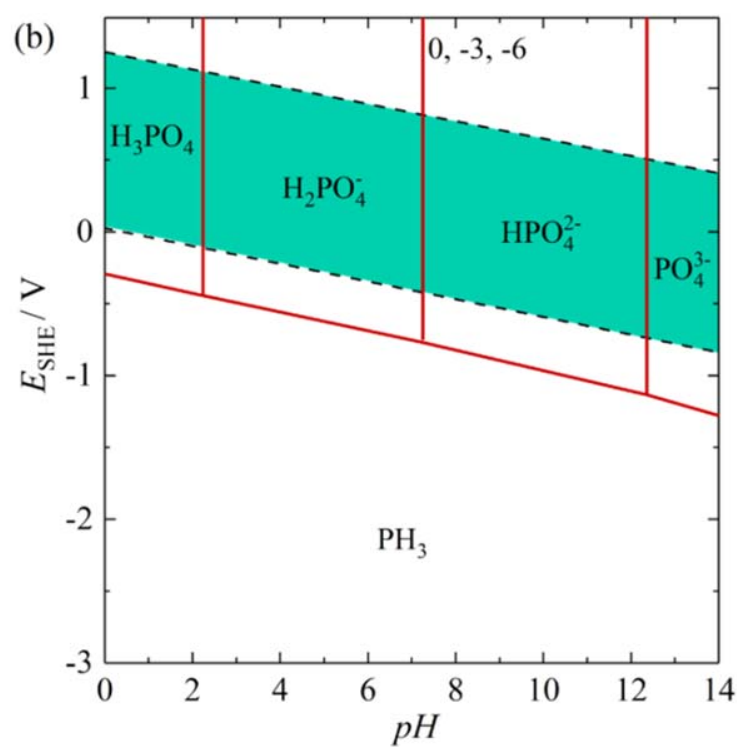

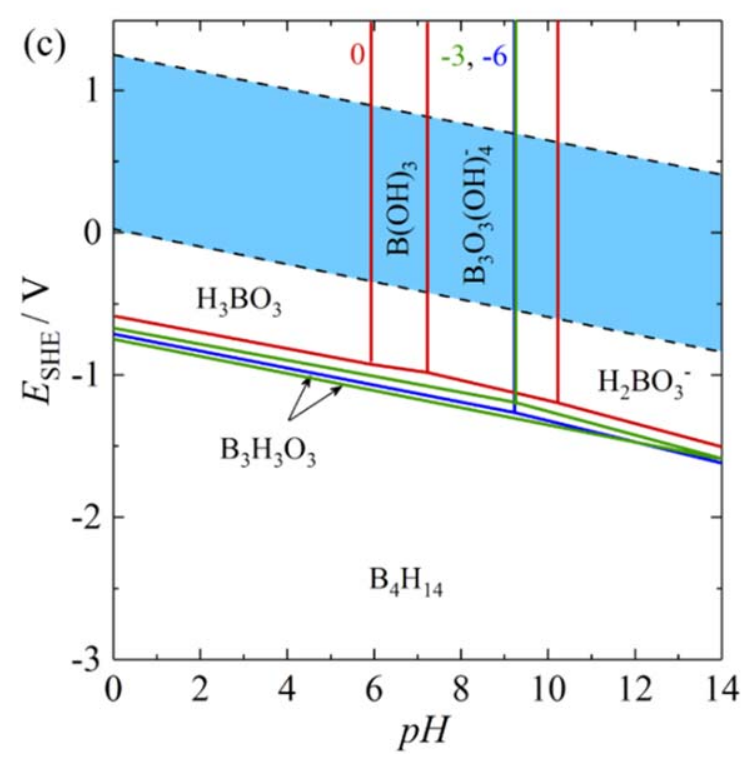

Figure 2. Eh-pH diagrams for (a) citrate, (b) phosphorous, and (c) boron in aqueous electrolytes. These diagrams are constructed at molar concentrations of dissolved species per liter of water with exponents of $0,-3$, and -6 at 298. 

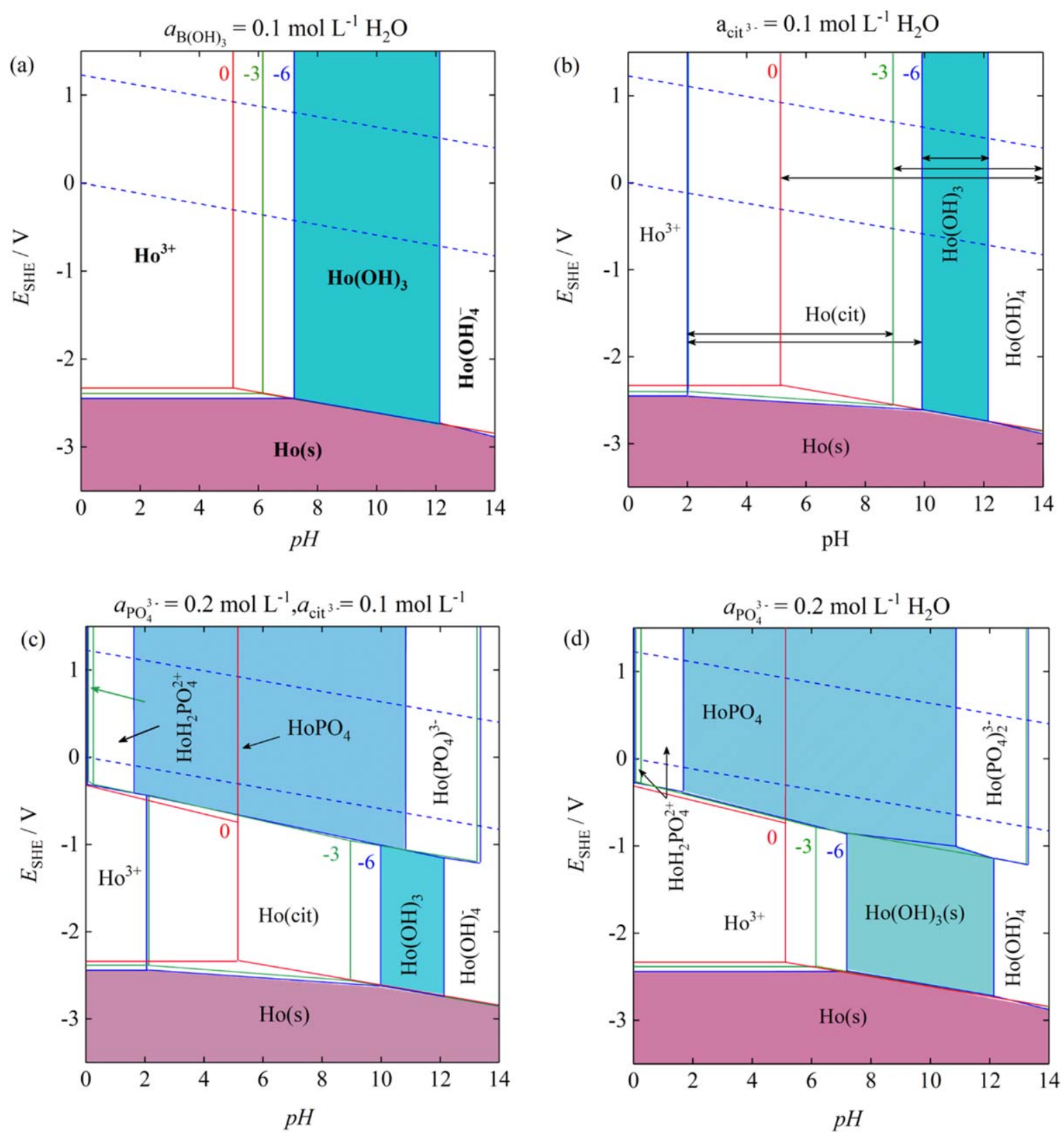

Figure 3. Eh- $\mathrm{pH}$ diagrams at molar concentrations of dissolved Ho with exponents $0,-3$, and -6 in (a) $\mathrm{Ho}-\mathrm{H}_{2} \mathrm{O}-0.1 \mathrm{M}$ borate buffer (pH 9.0 ) system, (b) $\mathrm{Ho}-\mathrm{H}_{2} \mathrm{O}-0.1 \mathrm{M}$ citrate buffer ( $\mathrm{pH}$ 6.0), (c) $\mathrm{Ho}-\mathrm{H}_{2} \mathrm{O}-0.2 \mathrm{M}$ phosphate-0.1 M citrate buffer ( $\mathrm{pH}$ 7.6), and (d) $\mathrm{Ho}-\mathrm{H}_{2} \mathrm{O}-0.2 \mathrm{M}$ phosphate buffer (pH 8.4) at $298 \mathrm{~K}$. The shaded areas indicate the passive and immune regions at $10^{-6}$ concentration.

shows the large stability domain of $\mathrm{Ho}(\mathrm{cit})$ particularly at lower concentrations of dissolved Ho. The negative free energy of aqueous Ho(cit) will eventually lead to the formation of soluble complexes and it is, therefore, possible that citrate ions will favor the formation of an unstable anodic film in the $\mathrm{pH}$ range of 4-6.5.

Ho- $\mathrm{H}_{2} \mathrm{O}$-citrate-phosphate or $\mathrm{Ho}-\mathrm{H}_{2} \mathrm{O}$-phosphate systems.The Eh-pH diagram of phosphorous shows that oxides of phosphorous are very soluble in water and promote the formation of soluble complexes $\mathrm{H}_{2} \mathrm{PO}_{4}{ }^{-}, \mathrm{HPO}_{4}{ }^{2-}, \mathrm{PO}_{4}{ }^{3-}$ in most of the $\mathrm{pH}$ range (Fig. 2b). Figures $3 \mathrm{c}$ and $3 \mathrm{~d}$ present the influence of phosphate either alone or in the presence of citrate on the $\mathrm{Ho}-\mathrm{H}_{2} \mathrm{O}$ system. At $1 \mathrm{M}$ concentration of dissolved $\mathrm{Ho}, \mathrm{Ho}(\mathrm{OH})_{4}$ and $\mathrm{HoPO}_{4}$ species cover the entire $\mathrm{pH}$ range and inhibit the migration of $\mathrm{Ho}^{3+}$ ions into the electrolyte as can be seen from red lines. Reduced concentration of dissolved $\mathrm{Ho}$ expands the $\mathrm{HoPO}_{4}$ stability domain. However, the formation of relatively stable aqueous $\mathrm{Ho}(\mathrm{cit})$ restricts the $\mathrm{Ho}(\mathrm{OH})_{3}$ stability field in phosphate-citrate buffer (green and blue lines). The shrinkage of $\mathrm{Ho}(\mathrm{OH})_{3}$ domain and affinity of $\mathrm{Ho}(\mathrm{cit})$ towards electrolytes may affect the anodizing of $\mathrm{Ho}$ in phosphate-citrate when comparing it to the $\mathrm{Ho}-\mathrm{H}_{2} \mathrm{O}$-phosphate counterpart. It is also known that anodizing in phosphate-containing electrolytes provides few advantages over other acidic or basic electrolytes. Phosphates are less corrosive when compared with other electrolytes. This effect is attributed to the strong absorption of phosphate anions on the metal oxide surface. They also exhibit strong complexing power towards most metal cations (Table I), consequently, phosphate anions can strongly affect the surface chemistry of the metal oxide. F. H. Firsching et al. reported that phosphates of rare-earth elements are highly insoluble in water and a pure solution of rareearth phosphates contains $10^{-13} \mathrm{M}$ concentrations of rare-earth phosphates. $^{29}$ It is therefore probable that anodizing in phosphate- 
containing electrolytes can form stable films on Ho as well as on other rare-earth metals, owing to their very similar electrochemical properties.

Solubility diagrams. - In order to further understand the stability fields prior to actual anodic oxidation, solubility diagrams of Ho in citrate, phosphate, and borate are also simulated for better visualization of predominance area of passivity and corrosion using Medusa software. Figure 4 presents the solubility diagrams at molar concentrations of Ho with exponents of $0,-3$, and -6 per litre of $\mathrm{H}_{2} \mathrm{O}$ at $298 \mathrm{~K}$ for hydroxide formation only. The influence of different species on $\mathrm{Ho}^{3+}$ solubility suppression is also shown. In agreement with $\mathrm{Eh}-\mathrm{pH}$ diagrams for hydroxide formation, $\mathrm{B}(\mathrm{OH})_{3}$ has no effect on expansion or shrinkage of solubility domain of $\mathrm{Ho}(\mathrm{OH})_{3}$ and shows a similar trend as in $\mathrm{Ho}-\mathrm{H}_{2} \mathrm{O}$ system (see Figs. $3 \mathrm{a}, 4 \mathrm{a}$ ), while the addition of $0.1 \mathrm{M} \mathrm{cit}^{3-}$ in $\mathrm{Ho}-\mathrm{H}_{2} \mathrm{O}$ system not only contracts the $\mathrm{Ho}(\mathrm{OH})_{3}$ domain but also shifts the stability region towards the alkaline side (see Figs. 3b, 4b). The obvious reason for the change in predominance area is the relatively high Gibbs free energy (negative) of aqueous Ho(cit) soluble complex as discussed above. Finally, the presence of phosphate in $\mathrm{Ho}-\mathrm{H}_{2} \mathrm{O}$ or in
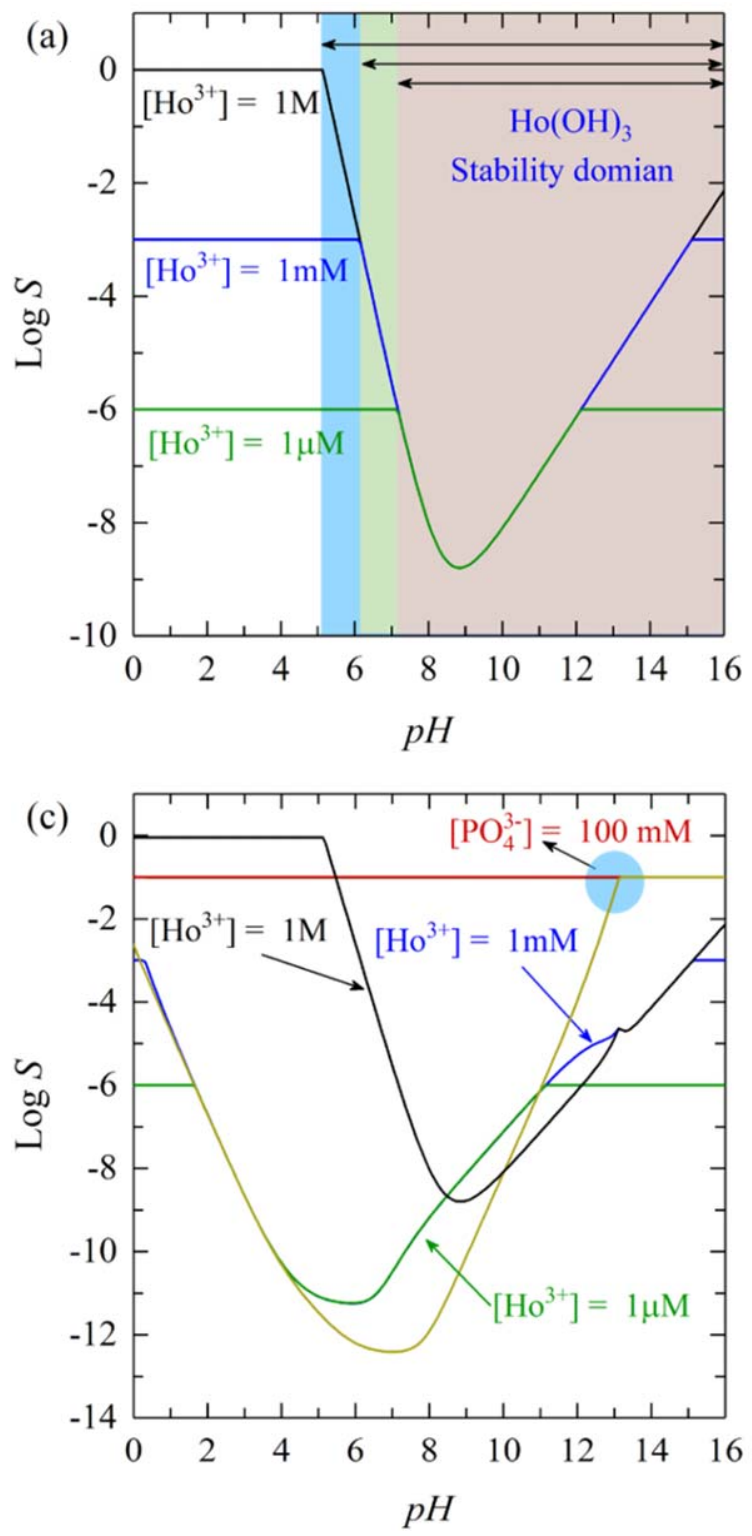

Ho- $\mathrm{H}_{2} \mathrm{O}$ - citrate system not only affects the stability domain of $\mathrm{Ho}(\mathrm{OH})_{3}$ by the formation of $\mathrm{HoPO}_{4}$ but also significantly inhibits the solubility of $\mathrm{Ho}^{3+}$ cations (Figs. $3 \mathrm{c}, 3 \mathrm{~d}-4 \mathrm{c}, 4 \mathrm{~d}$ ). The effect of phosphate addition has already been discussed in detail in the Eh-pH section. Based on these simulations, it is expected that electrolytes containing citrate are not suitable for the anodic oxidation of Ho, while phosphate provides the optimum protection of $\mathrm{Ho}^{3+}$ against corrosion through the formation of stable $\mathrm{HoPO}_{4}$ species compared with $\mathrm{Ho}(\mathrm{OH})_{3} / \mathrm{Ho}_{2} \mathrm{O}_{3}$, though incorporation of $\mathrm{PO}_{4}{ }^{3-}$ into the film is still unclear. Lastly, the presence of $\mathrm{B}(\mathrm{OH})_{3}$ does not affect the thermodynamics of $\mathrm{Ho}-\mathrm{H}_{2} \mathrm{O}$ system in conventional Eh-pH diagrams.

First-principles DFT calculations.-In principle, conventional Eh- $\mathrm{pH}$ diagrams and simulation of Eh- $\mathrm{pH}$ diagrams from existing literature data using Medusa and Geochemist workbench software's account for materials only at equilibrium and gives no insight for the electrochemical stability of metastable materials which may form during electrochemical synthesis process. ${ }^{30}$ There is clearly a need for an advance approach to identify possible stable phases in a given system. To overcome this limitation, first-principles DFT method by
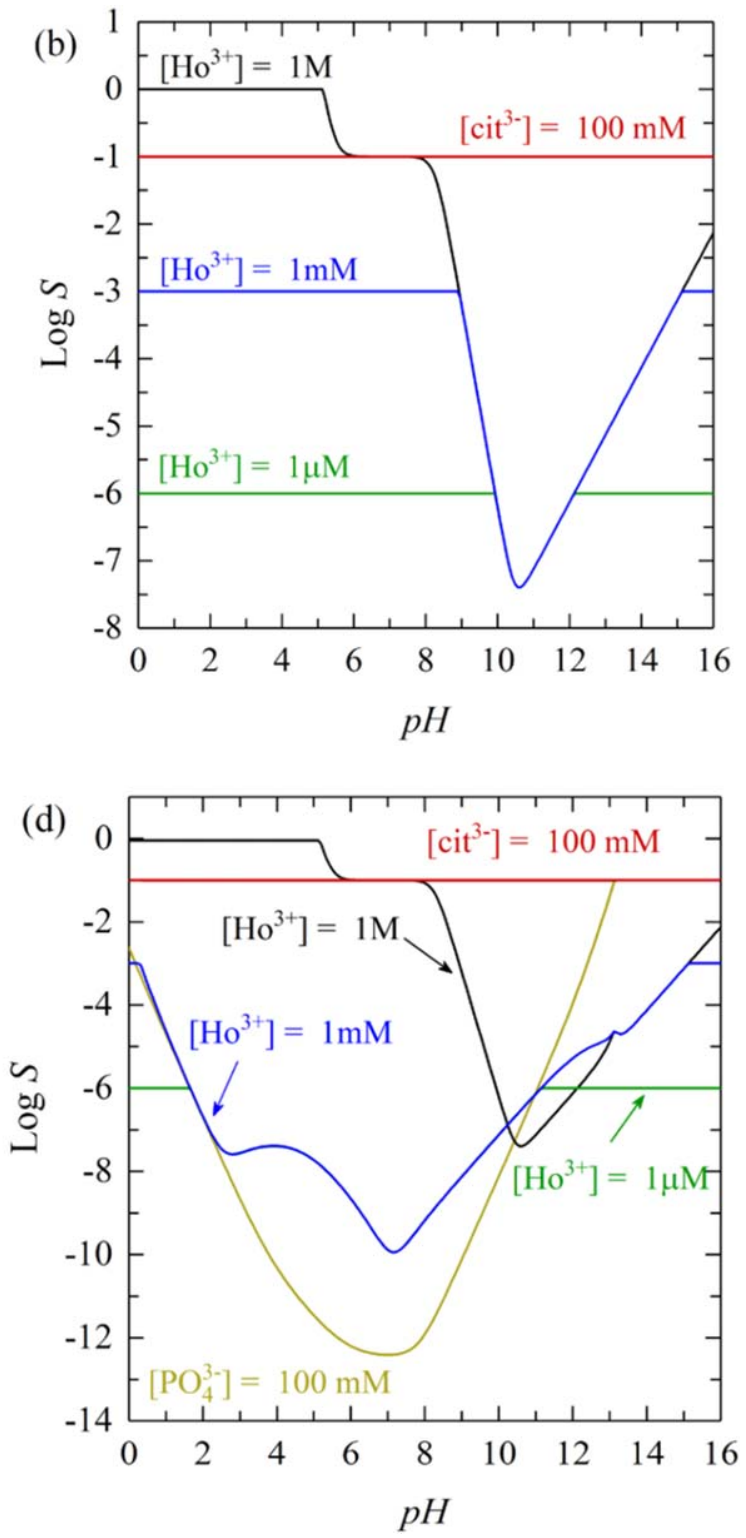

Figure 4. Solubility diagrams at molar concentrations of dissolved $\mathrm{Ho}$ with exponent of $0,-3$, and -6 per liter of water in (a) $\mathrm{Ho}_{-} \mathrm{H}_{2} \mathrm{O}$ system, (b) $\mathrm{Ho}-\mathrm{H}_{2} \mathrm{O}-0.1 \mathrm{M} \mathrm{cit}^{3-}$ system, (c) $\mathrm{Ho}-\mathrm{H}_{2} \mathrm{O}-0.2 \mathrm{M} \mathrm{PO}_{4}{ }^{3-}$ system, (d) $\mathrm{Ho}-\mathrm{H}_{2} \mathrm{O}-0.1 \mathrm{M} \mathrm{cit}{ }^{3-}-0.2 \mathrm{M} \mathrm{PO}_{4}{ }^{3-}$ system. The diagrams are simulated at $298 \mathrm{~K}$. 

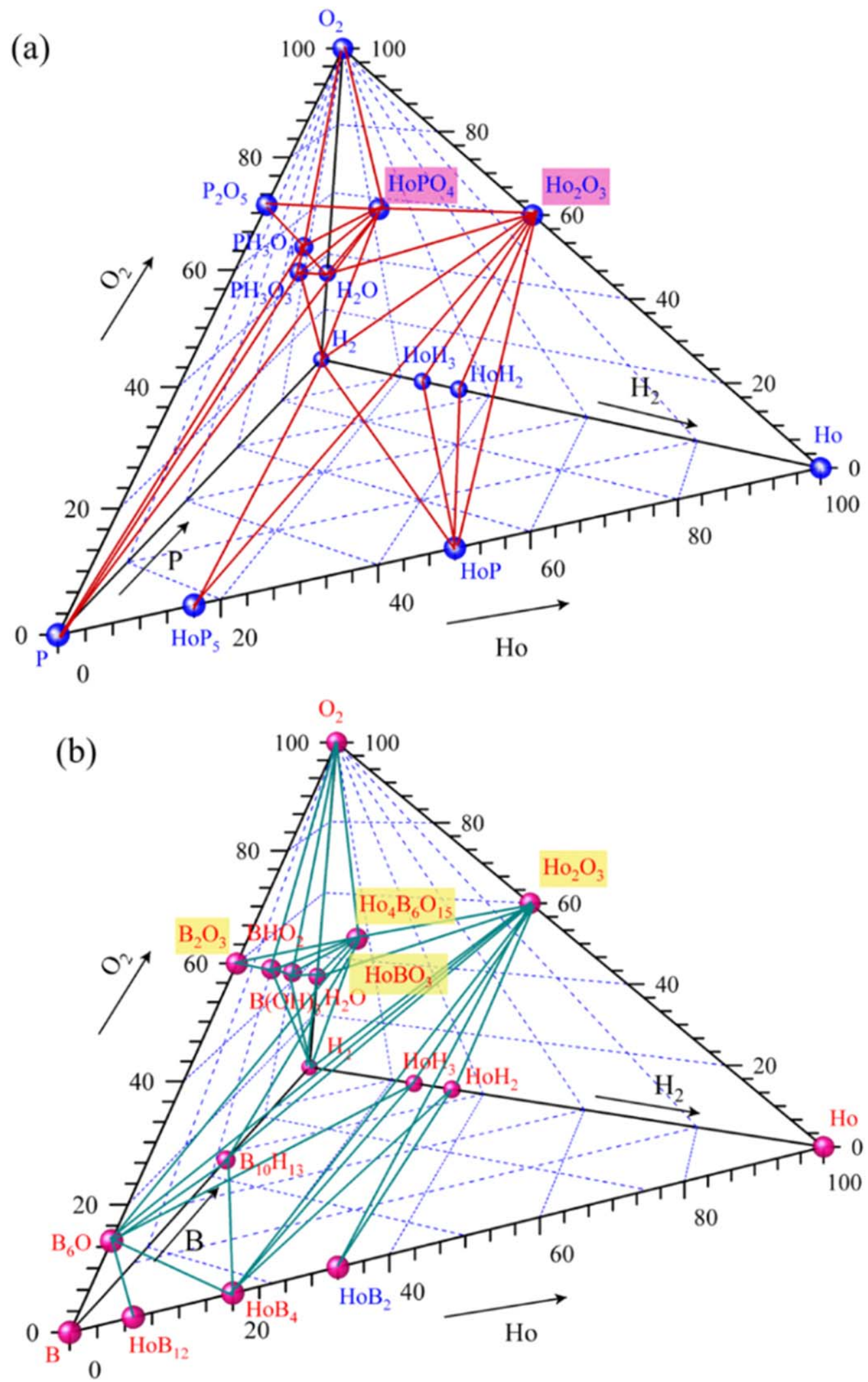

Figure 5. Compositional Phase diagrams of (a) $\mathrm{Ho}-\mathrm{P}-\mathrm{H}_{2}-\mathrm{O}_{2}$ and (b) $\mathrm{Ho}-\mathrm{B}-\mathrm{H}_{2}-\mathrm{O}_{2}$ systems. These phase diagrams are simulated from first-principles DFT calculations using existing experimental and computational data at room temperature.

K. A. Persson et al. ${ }^{26}$ was further used as a more insightful approach for accurate prediction of solid-aqueous reaction energies. K. A. Persson and co-workers ${ }^{26}$ performed first-principles Car-Parinello molecular dynamics for simulations of aqueous states.
Though, first- principles methods are gaining premium importance in various fields as high through-put calculations approach, ${ }^{31-37}$ the advantage of Persson method is the direct incorporation of stable phases from compositional phase diagrams 

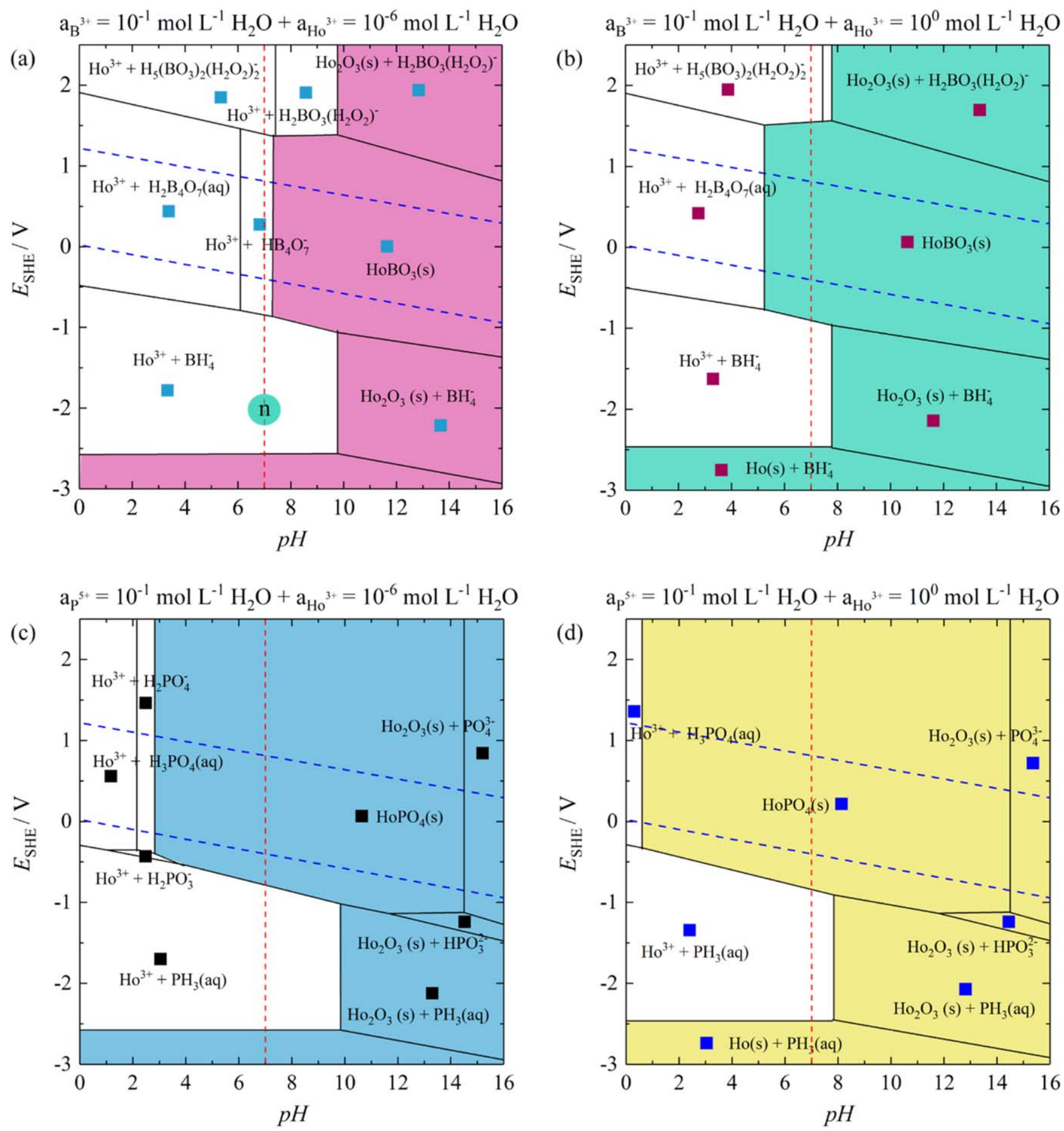

Figure 6. Simulation of Eh-pH diagrams from first- principles DFT calculations at molar concentrations of dissolved Ho with exponents (a) -6 , (b) 0 in $\mathrm{Ho}-\mathrm{H}_{2} \mathrm{O}-0.1 \mathrm{M}$ B system and (c) -6 , (d) 0 in $\mathrm{Ho}-\mathrm{H}_{2} \mathrm{O}-0.1 \mathrm{M} \mathrm{P}$ system. The shaded areas indicate the passive regions.

of a given system into the $\mathrm{Eh}-\mathrm{pH}$ diagrams to maximize the prediction of solid-aqueous equilibria. ${ }^{38}$ An example of DFT calculations is shown in Figs. 5-6, where all possible stable phases with minimum Gibbs's free energies are directly incorporated from quaternary phase diagrams of $\mathrm{Ho}-\mathrm{P}-\mathrm{H}_{2}-\mathrm{O}_{2}$ and $\mathrm{Ho}-\mathrm{B}-\mathrm{H}_{2}-\mathrm{O}_{2}$ complex systems into the $\mathrm{Eh}-\mathrm{pH}$ diagrams. For instance, existing literature data (Fig. 3a) do not address the presence of stable $\mathrm{HoBO}_{3}$, $\mathrm{B}_{2} \mathrm{O}_{3}$, and $\mathrm{Ho}_{2} \mathrm{O}_{3}$ phases as conventional $\mathrm{Eh}-\mathrm{pH}$ diagrams do not incorporate phases directly from compositional phase diagrams. On the other hand, by simultaneously considering phase diagrams of Ho- $-\mathrm{B}-\mathrm{O}_{2}-\mathrm{H}_{2}$ and $\mathrm{Ho}-\mathrm{P}-\mathrm{O}_{2}-\mathrm{H}_{2}$ systems (Figs. 4a, 4b) and $\mathrm{Eh}-\mathrm{pH}$ diagrams of $\mathrm{B}-\mathrm{Ho}-\mathrm{H}_{2} \mathrm{O}$ and $\mathrm{P}-\mathrm{Ho}-\mathrm{H}_{2} \mathrm{O}$ systems (Figs. 5a, 5b), it is now possible to extend the existing Eh-pH diagrams stability field to find new applications.

It is very clear from Figs. $6 \mathrm{a}, 6 \mathrm{c}$ that both $0.1 \mathrm{M}$ phosphate and $0.1 \mathrm{M}$ borate containing aqueous electrolytes are thermodynamically feasible to grow protective films between $\mathrm{pH}$ 7.0-9.0 at high Faradaic efficiency $\left(\mathrm{a}_{\mathrm{Ho}}{ }^{3+}=10^{-6} \mathrm{ML}^{-1} \mathrm{H}_{2} \mathrm{O}\right)$. Moreover, we have further estimated enthalpy change, $\Delta \mathrm{H}$ of various oxides for binary systems such as $\mathrm{Ho}_{2} \mathrm{O}_{3}-\mathrm{H}_{2} \mathrm{O}, \mathrm{Ho}_{2} \mathrm{O}_{3}-\mathrm{B}_{2} \mathrm{O}_{3}, \mathrm{Ho}_{2} \mathrm{O}_{3}-\mathrm{P}_{2} \mathrm{O}_{5}$, and $\mathrm{Ho}_{2} \mathrm{O}_{3}-\mathrm{C}_{6} \mathrm{H}_{8} \mathrm{O}_{7}$ using DFT calculations neglecting the entropic contribution (as can be seen in Convex Hull diagrams in Fig. 7). It was found out that $\mathrm{Ho} 2 \mathrm{O} 3$ possesses more negative $\Delta \mathrm{H}$ value $(\Delta \mathrm{H}$ for $\mathrm{Ho}_{2} \mathrm{O}_{3}=-3.892 \mathrm{eV}$ atom- 1 or $-1878 \mathrm{~kJ} \mathrm{~mol}^{-1}$ as $1 \mathrm{eV}$ atom ${ }^{-1}$ 

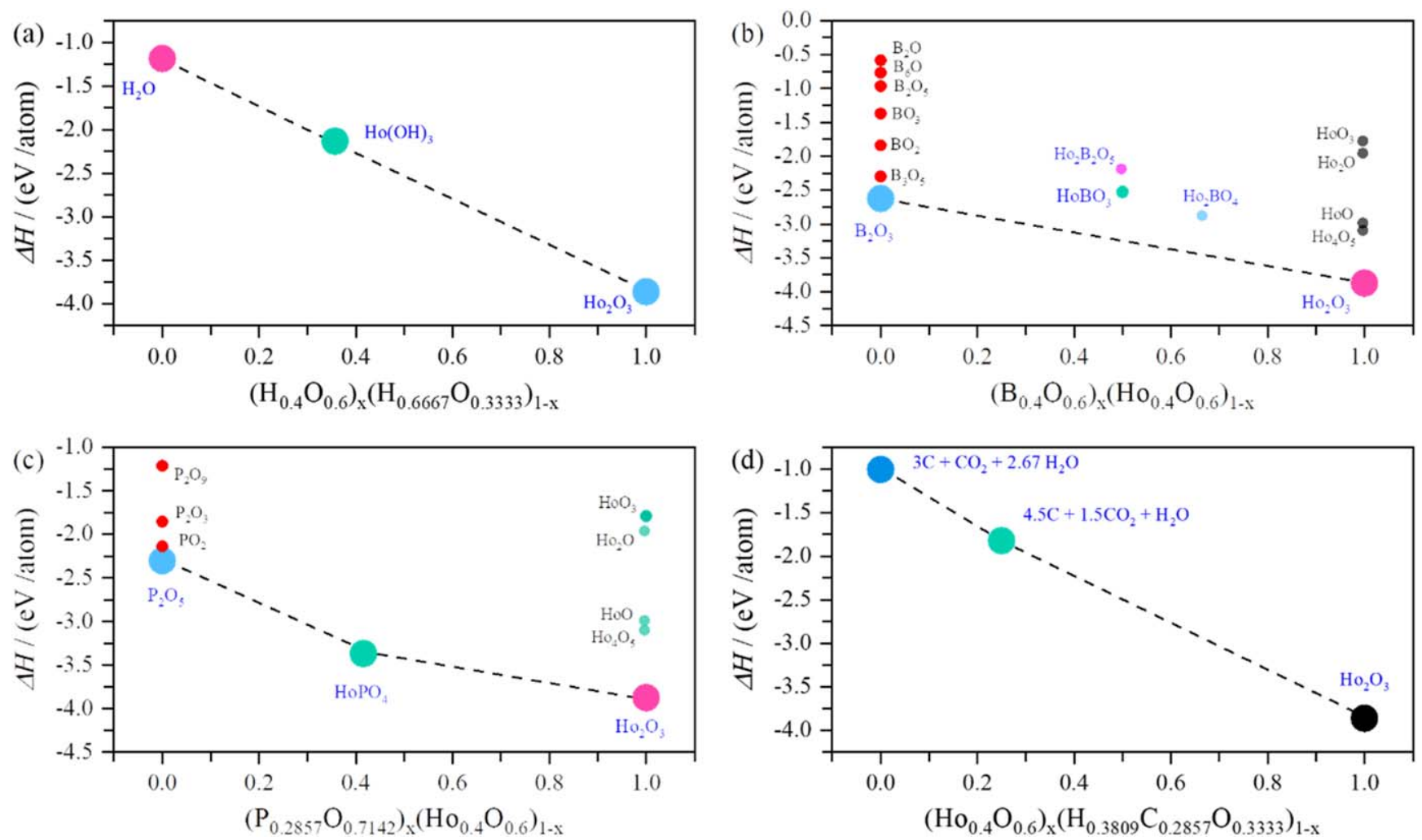

Figure 7. Enthalpy change, $\Delta \mathrm{H}$ of oxides formation for binary (a) $\mathrm{Ho}_{2} \mathrm{O}_{3}-\mathrm{H}_{2} \mathrm{O}$, (b) $\mathrm{Ho}_{2} \mathrm{O}_{3}-\mathrm{B}_{2} \mathrm{O}_{3}$, (c) $\mathrm{Ho}_{2} \mathrm{O}_{3}-\mathrm{P}_{2} \mathrm{O}_{5}$, and (d) $\mathrm{Ho}_{2} \mathrm{O}_{3}-\mathrm{C}_{6} \mathrm{H}_{8} \mathrm{O}_{7}$ systems using firstprinciples DFT calculations. The relative stability of $\mathrm{Ho}_{2} \mathrm{O}_{3}$ among others oxides in different binary systems can be clearly seen.

$\left.=96.5 \mathrm{~kJ} \mathrm{~mol}^{-1}\right)$ among $\mathrm{HoPO}_{4}, \mathrm{~B}_{2} \mathrm{O}_{3}, \mathrm{~B}(\mathrm{OH})_{3}, \mathrm{Ho}(\mathrm{OH})_{3}$, or citrate phases in DFT calculations. Thus, it is likely that the growth of pure $\mathrm{Ho}_{2} \mathrm{O}_{3}$ film can be promoted at high Faradaic efficiency in borate, phosphate, and phosphate-citrate buffers between $\mathrm{pH}$ 7.0-9.0.

Thereby, the electrolyte selection and experimental scheme for the present study is designed based on these aforementioned simulation approaches and is presented in Fig. 8, which discloses the interaction of various electrolyte species with Ho surface, use of SDCM to grow localized anodic film as well as the growth of $\mathrm{Ho}_{2} \mathrm{O}_{3}$. The citrate buffer having a $\mathrm{pH}$ range of $4.5-6.0$ is also employed for the validation of our thermodynamics scheme.

$\boldsymbol{X R D}$ and SEM.-Before performing any electrochemical studies, the crystallographic pattern and surface features of Ho were examined. Figure 9 shows the XRD pattern and SEM surface morphology of thermally evaporated $\alpha$-Ho on a glass substrate. An exemplary surface morphology after potential sweep anodizing to $10 \mathrm{~V}\left(100 \mathrm{mV} \mathrm{s}^{-1}\right)$ in $0.2 \mathrm{M}$ phosphate buffer is shown in Fig. 9b. The as-evaporated film which was approximately $500 \mathrm{~nm}$ thick reveals the typical hcp phase of $\alpha$-Ho (space group no. P63/mmc and PDF no. 01-089-2927). The surface image demonstrates the uniform fine-grained morphology with an average grain size of $<\sim 50 \mathrm{~nm}$. The formation of the anodic film is recognizable from the change in surface morphology of as-evaporated Ho thin film. The absence of any surface feature and lack of porosity suggests the barrier-type amorphous film growth on Ho surface.

Potentiodynamic anodizing.-After analysis of the thermodynamic behaviour, anodizing of thermally evaporated Ho was performed in selected electrolytes. The summary of electrolytes used for anodizing is given in Table II. The electrolytes are selected in such a way to cover the most frequently used oxidation window (pH 7-9) for barrier-type film on most widely investigated $\mathrm{Al}$ anodic system Al. For the investigation of anodizing behaviour and dielectric properties of anodic films on Ho, a suitable selection of the sweep rate is also important. Therefore, at first, the selection of sweep rate was decided from the cyclic voltammograms recorded at different sweep rates $\left(10,50,100,200,500\right.$, and $\left.1000 \mathrm{mV} \mathrm{s}^{-1}\right)$. For this purpose, two electrolytes having different $\mathrm{pH}$ namely $0.2 \mathrm{M}$ phosphate buffer $(\mathrm{pH} 8.4$ ) and $0.1 \mathrm{M}$ ammonium pentaborate tetrahydrate $(\mathrm{pH} 7.6)$ were employed based on the fact that both of these electrolytes do not enhance the dissolution domain of $\mathrm{Ho}^{3+}$ (Figs. 3a, 3d). Figure 10a displays the current transient recorded at different sweep rates. A non-steady state current density is evident throughout the experiment at all sweep rates and the magnitude of current density gradually increases with the rise in sweep rate. Up to $\sim 3 \mathrm{~V}$ and $100 \mathrm{mV} \mathrm{s}^{-1}$, a nearly constant current plateau typical to a steady state condition was observed. It is obvious that 10 and $50 \mathrm{mV} \mathrm{s}^{-1}$ sweep rates are not appropriate for growing a uniform film on Ho in $0.2 \mathrm{M}$ phosphate buffer due to the absence of a current response typical to the passive film. Above $100 \mathrm{mV} \mathrm{s}^{-1}$, the current density rapidly rises even at the onset of anodizing. Above $3 \mathrm{~V}$, the current rises continuously without the appearance of any current plateau from 100 to $1000 \mathrm{mV} \mathrm{s}^{-1}$. At higher sweep rates of 500 and $1000 \mathrm{mV} \mathrm{s}^{-1}$, the dependence of current density on the anodizing voltage follows a quasi-exponential transient between $3-4.5 \mathrm{~V}$. Thereafter, the non-steady state rise in current density slows down with further increase in formation voltage. It is well-known from the high field conduction model that the ionic current density responsible for amorphous film growth will display constant current plateau (steady-state) during anodic polarization and the current transient for an ideal passive film will approach to zero upon reversal of potential scan. ${ }^{39}$ In the present case, inherent metal surface texture, oxygen gas and/or side reactions such as various complex formation, adsorption of phosphate ions on metal surface, or variation in film structure upon anodizing might be responsible for this non-steady state current density. Similar current response as at $100 \mathrm{mV}^{-1}$ has been reported by M. Herranen et al., ${ }^{40}$ A. Zafora et al., ${ }^{41}$ and more recently by J. P. Kollender et al. ${ }^{42}$ during anodizing of titanium in sulphuric acid and was described in terms of ionic (steady-state) and 
(a) Borax Buffer

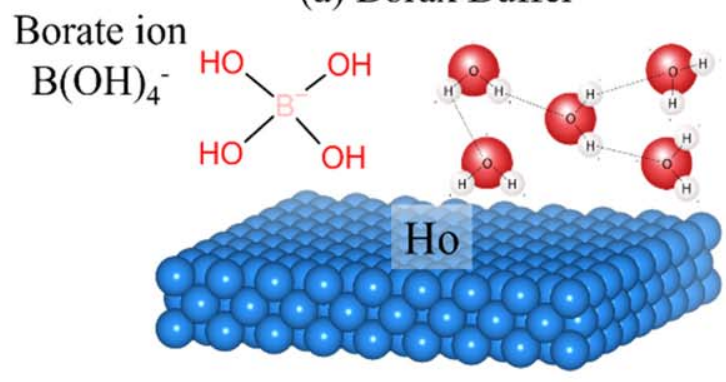

(b) Ammonium pentaborane tetrahydrate

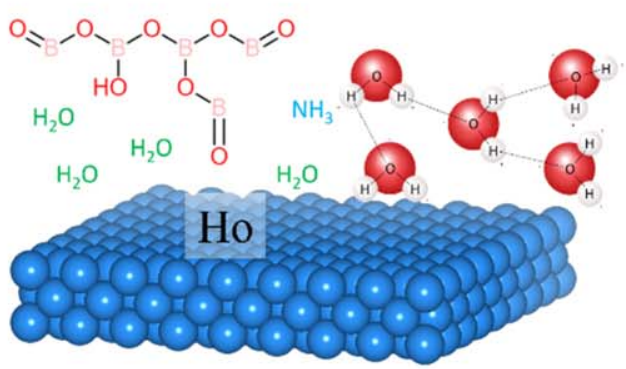

(e) Holmium oxidation in different electrolytes

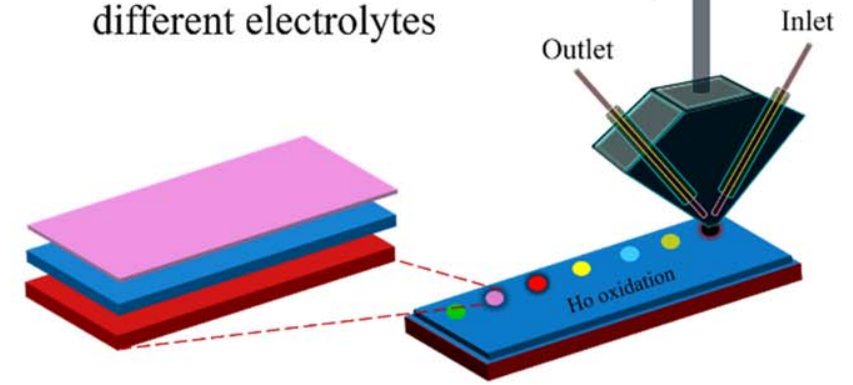

(d) Citrate buffer

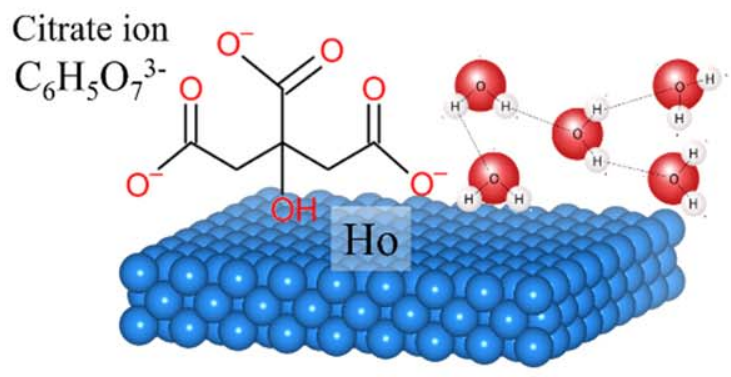

(c) Phosphate buffer

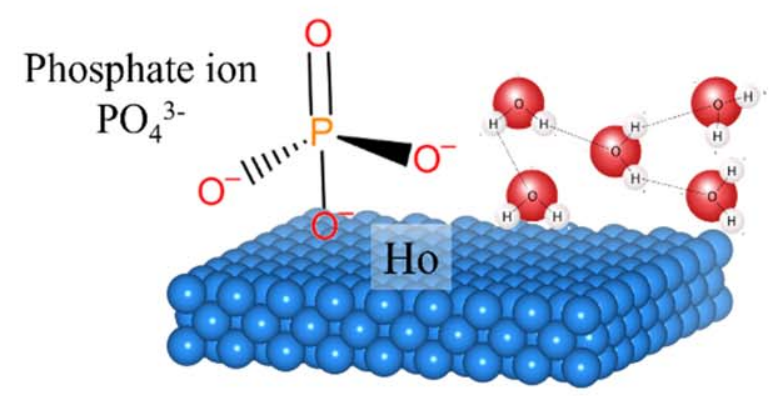

(f) Holmium oxide $\mathrm{Ho}^{3+} \mathrm{O}^{2-}$

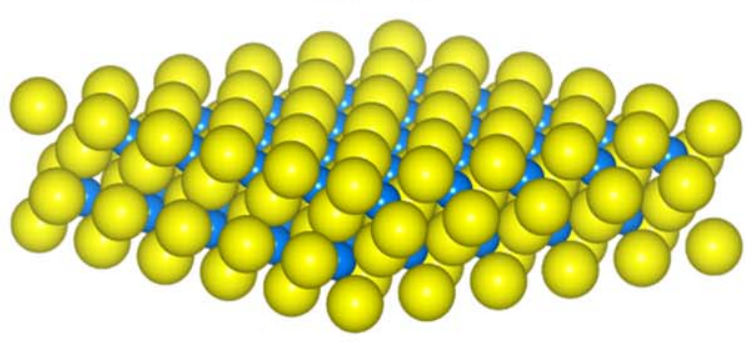

Figure 8. Experimental scheme comprising of oxidation of evaporated Ho thin film in aqueous electrolytes having different $\mathrm{pH}$ (a) borax buffer, (b) citrate buffer, (c) ammonium pentaborate tetrahydrate (non-buffered), (d) phosphate buffer, (e) use of scanning droplet microscopy on evaporated film surface, and (f) formation of holmium oxide.

\footnotetext{
Table II. Summary of different electrolytes used for Ho anodizing.

Selected electrolytes for Ho anodizing $\mathrm{pH}$

1. Borate $(0.1 \mathrm{M}$ boric acid +0.03 sodium hydroxide) buffer $(\mathrm{BA})$

2. Ethylene glycol-0.2 M Phosphate buffer (EG-P)

3. 0.2 M Phosphate (Potassium phosphate + disodium Phosphate) buffer $(\mathrm{P})$

4. Citrate-Phosphate $(0.1 \mathrm{M}$ citric acid monohydrate $+0.2 \mathrm{M}$ disodium phosphate) buffer (Cit-P)

5. 0.1 M Ammonium pentaborate tetrahydrate (B)

6. 0.2 M Phosphate (Potassium phosphate + disodium Phosphate) buffer $(\mathrm{P})$

7. Citrate $(0.1 \mathrm{M}$ citric acid monohydrate $+0.1 \mathrm{M}$ trisodium citrate dihydrate) buffer (Cit)

8. Citrate $(0.1 \mathrm{M}$ citric acid monohydrate $+0.1 \mathrm{M}$ trisodium citrate dihydrate) buffer (Cit)

9. Citrate $(0.1 \mathrm{M}$ citric acid monohydrate $+0.1 \mathrm{M}$ trisodium citrate dihydrate) buffer (Cit)

10. Citrate $(0.1 \mathrm{M}$ citric acid monohydrate $+0.1 \mathrm{M}$ trisodium citrate dihydrate) buffer (Cit)

electronic (non-steady state) currents. C. G. Dunn reported that flaws or isolated points on the surface are associated with the electronic currents and in principle have no effect on the electric field strength in flaw-free areas, therefore, electronic currents only produce an higher average current density without affecting the growth rate. ${ }^{43}$ There is an equal probability that the extremely fine-grained Ho surface (Fig. 9b) provides a relatively large grain boundary area and this inherent structure having large grain-boundaries (as defective area) leads to 


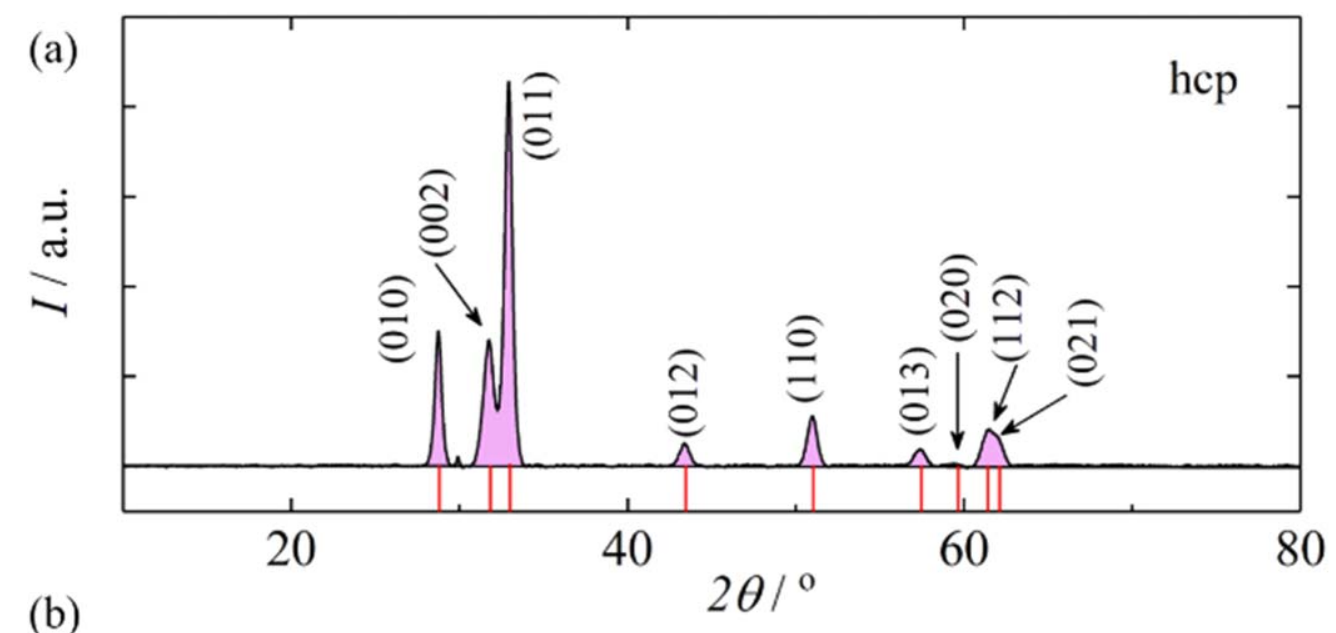

(b)
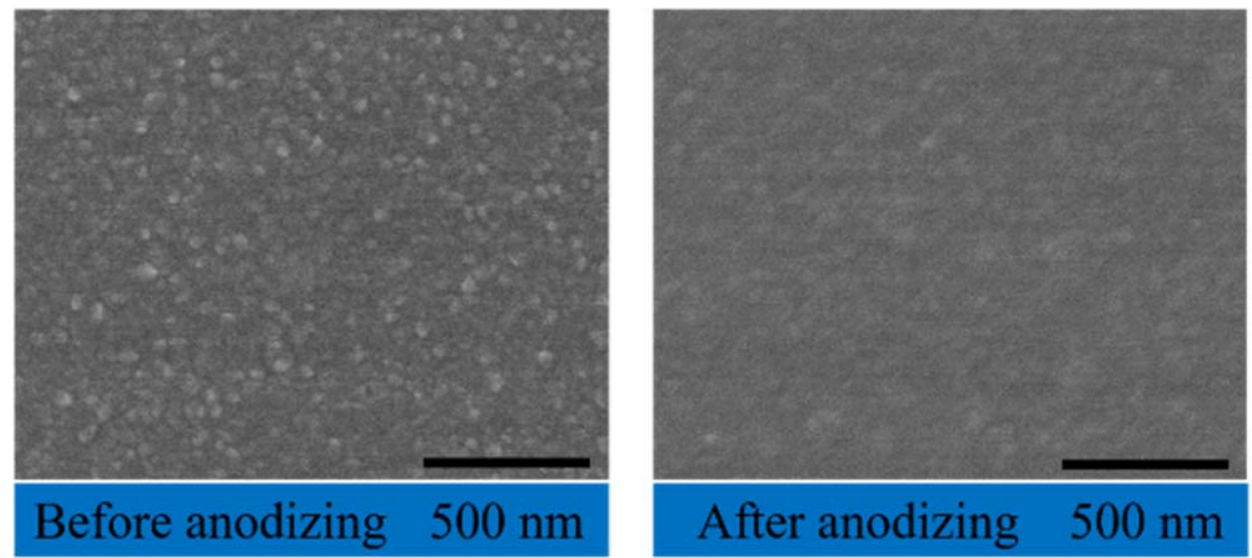

Figure 9. (a) XRD pattern of thermally evaporated holmium thin film (b) Scanning electron micrographs of the surfaces of as-deposited and as-anodized films. Anodizing is carried out potentiodynamically at a sweep rate of $100 \mathrm{mV} \mathrm{s}^{-1}$ to 10 Vat room temperature in $0.2 \mathrm{M}$ phosphate buffer (pH 8.4).

localized electronic current densities. B. Hirschorn et al. ${ }^{44}$ also described the importance of surface charge distribution associated with local surface elements probably arising from surface roughness. Moreover, if cations go into the electrolyte by field-assisted ejection, this will also lead to an increase in current density. However, inductively coupled plasma optical emission spectroscopy (ICPOES) analysis in a separate study reveals the negligible dissolution of holmium (14 ppb) in phosphate buffer. ${ }^{25}$ This annuls the supposition of current rise due to field-assisted ejection of cations. J. J. Randel et al. observed that current efficiency in aqueous phosphate electrolytes largely depends on the electrolyte concentration, temperature, and stirring rate and further reported that reduction in current efficiency is associated to the increased acidity at the oxide/electrolyte interface, leading to the formation of soluble complexes during aluminum anodizing. ${ }^{38}$ However, in the present study, similar cyclic voltammograms ( $\mathrm{CV}$ with the flowing electrolyte is not shown here) in phosphate buffer with and in stagnant electrolyte during anodizing indicate that stirring rate and localized acidity apparently do not influence the current transient.

An open question may arise whether the phosphate buffer is responsible for such current transient. To answer this question, anodizing was also performed in commonly used ammonium pentaborate electrolyte under similar conditions (Fig. 10c). Interestingly, Ho anodizing revealed the similar kind of behavior but at nearly half magnitude of current density, indicating that oxygen gas evolution and complex formation or structural changes in the anodic film are less pronounced in the presence of borate. The similar current response in two different electrolytes might be associated with the inherent structure of Ho upon anodizing.
Considering a flat non-porous anodic film of surface area, A at $100 \%$ Faradaic efficiency with Maxwell electric field strength, E being independent of time $t$ for a given value of sweep rate $\eta$, then the electric field across the anodic film can be used to determine the growth rate according to the following equation

$$
\frac{\mathrm{dx}}{\mathrm{dt}}=\left(\frac{1}{\mathrm{E}}\right) \frac{\mathrm{dV}}{\mathrm{dt}}
$$

where $x$ is the thickness of oxide film, $t$ is the anodizing time, and $\mathrm{V}$ is the formation potential. The growth rate can also be determined by incorporating the Faraday's law as

$$
\frac{\mathrm{dx}}{\mathrm{dt}}=\frac{\mathrm{jM}}{\mathrm{zF} \rho}
$$

where $\mathrm{M} / \mathrm{zF}$ is the electrochemical equivalent of oxide, $\mathrm{j}$ is the current density, and $\rho$ is the density of oxide. Equations 2 and 3 suggest that the growth rate depends on the sweep rate $(\eta=\mathrm{dV} / \mathrm{dt})$ as well as on the current density and that a higher growth rate can be achieved at high-sweep rate and current density.

In order to further simplify the understanding of film growth, Figs. 10b, 10d display the normalized current transient by sweep rate, $\eta$ (in units of capacity per unit area). A simple and useful relation relating capacity, film thickness, and anodizing charge can be expressed as follows

$$
\frac{\mathrm{C}}{\mathrm{A}}=\left(\frac{1}{\mathrm{~A}}\right) \frac{\mathrm{dq} / \mathrm{dt}}{\mathrm{dV} / \mathrm{dt}}=\frac{\varepsilon_{\mathrm{o}} \varepsilon}{\mathrm{x}}
$$



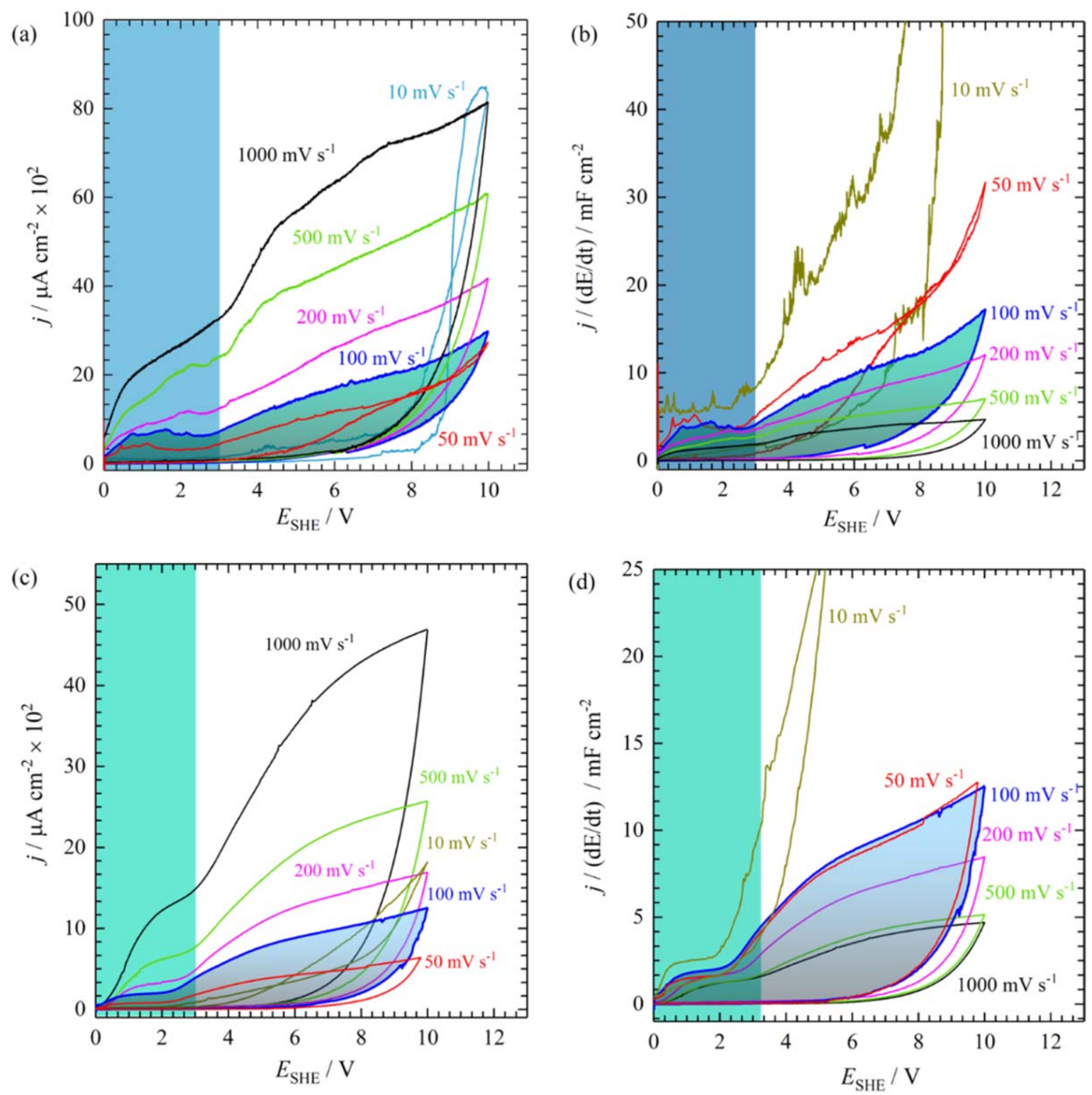

Figure 10. Cyclic voltamograms of thermally evaporated Ho at different sweep rates in (a) $0.2 \mathrm{M}$ phosphate buffer (pH 8.4 ) and (c) $0.1 \mathrm{M}$ ammonium pentaborate tetrahydrate ( $\mathrm{pH}$ 7.6). Normalized current density by sweep rate, $\eta$ in (b) $0.2 \mathrm{M}$ phosphate buffer ( $\mathrm{pH} 8.4$ ) and (d) $0.1 \mathrm{M}$ ammonium pentaborate tetrahydrate $(\mathrm{pH} 7.6)$.

Equation 4 can also be written in more simplified form as

$$
\frac{\mathrm{C}}{\mathrm{A}}=\frac{\mathrm{j}}{\eta}=\frac{\varepsilon_{\mathrm{o}} \varepsilon}{\mathrm{x}}
$$

Equation 5 describes that $\mathrm{j} / \eta$ varies inversely with the film thickness and a low value of $\mathrm{j} / \eta$ will lead to a higher growth rate. Following this equation, it is clear again from Figs. $10 \mathrm{~b} \& 10 \mathrm{~d}$ that $10 \mathrm{mV} \mathrm{s}^{-1}$ is not suitable for higher growth of anodic film, while higher sweep rates such as 500 and $1000 \mathrm{mV} \mathrm{s}^{-1}$ should be the optimum choice for film growth on Ho. Assuming diffusion dependent ionic migration across the film, the time to reach $10 \mathrm{~V}$ at 500 and $1000 \mathrm{mV} \mathrm{s}^{-1}$ is extremely short (20 and $10 \mathrm{~s}$ respectively) for realistic ionic migration, therefore, a relatively higher $\mathrm{j} / \eta$ value $\left(100 \mathrm{mV} \mathrm{s}^{-1}\right)$ was selected in the present study in order to ensure a sufficient time for ionic migration across the film under high electric field. At the same time, the anodic polarization curve should display the response being typical of the passive film. Thus, in the subsequent description, $100 \mathrm{mV} \mathrm{s}^{-1}$ sweep rate will be used to address the anodizing behavior of the film.
After suitable sweep rate selection, the anodizing behavior of thermally evaporated Ho was investigated in different electrolytes (Figs. 10a, 11a). Figure 11a illustrates that in each of the cyclic voltammograms corresponding to specific electrolytes, two distinct regions (already discussed in above section) are present irrespective of the electrolyte and $\mathrm{pH}$ value. Generally, REE's readily form hydroxides in alkaline solution, therefore, it is not surprising that borate buffer ( $\mathrm{pH}$ 9.0) leads to the lowest current density. However, it is noteworthy that addition of phosphate even in near neutral electrolyte $(\mathrm{pH} 7.1)$ can impede the dissolution of $\mathrm{Ho}^{3+}$ into the electrolyte. The formation of a stable film in phosphate alone or in combination with phosphate- citrate or phosphate- ethylene glycol (EG) will not only extend the oxidation window but also provide a solution for many industrial problems, where Ho can be used in contact with aqueous electrolytes. Though, it is not yet clear to us whether rare-earth phosphate adsorbs only on the surface and modifies the surface chemistry or actually is being incorporated into the anodic film.

Phosphorous species are usually incorporated into the anodic film as $\mathrm{PO}_{4}{ }^{3-}$ ions which are formed on the surface by the deprotonation 

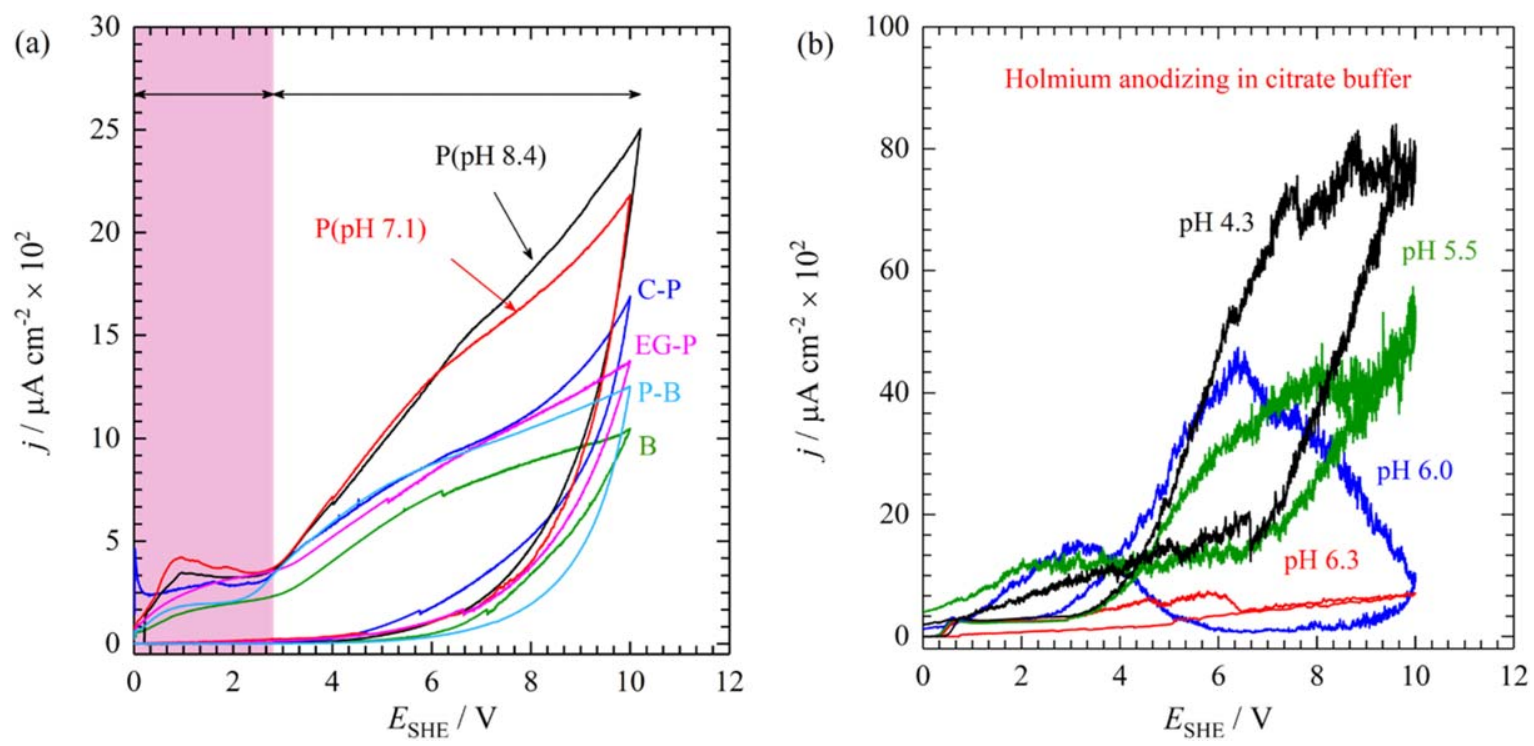

Figure 11. (a) cyclic voltamograms recorded during potentiodynamic anodizing of Ho to $10 \mathrm{~V}$ at a sweep rate of $100 \mathrm{mV} \mathrm{s}^{-1}$ in selected electrolytes having different $\mathrm{pH}$ (b) cyclic voltamograms in citrate electrolyte having different $\mathrm{pH}$. All data is recorded at room temperature.
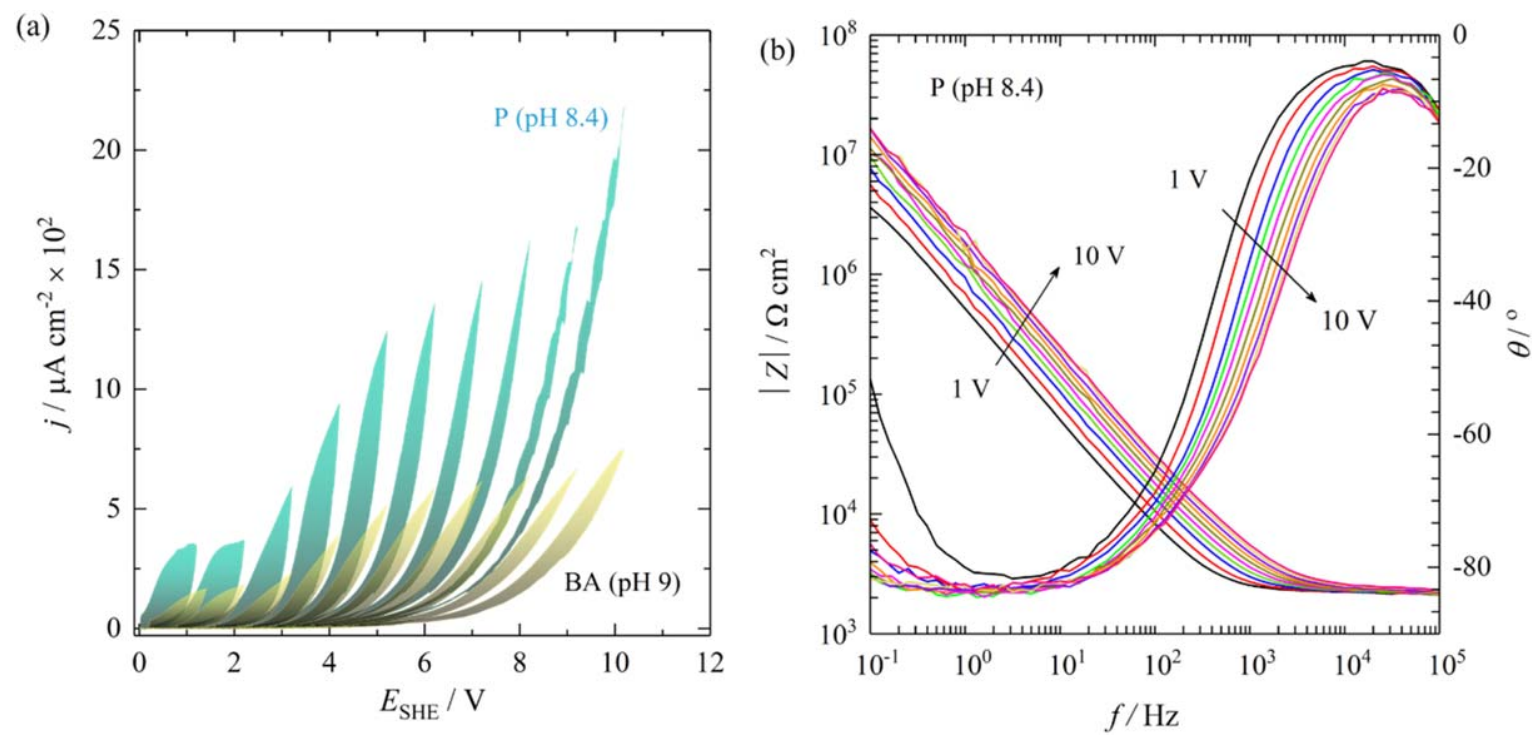

Figure 12. (a) Cyclic voltammograms on evaporated Ho thin film in $0.2 \mathrm{M}$ phosphate buffer ( $\mathrm{pH} 8.4$ ) and borate buffer ( $\mathrm{pH} 9.0$ ), (b) Bode plot during simultaneous CV measurements in $0.2 \mathrm{M}$ phosphate buffer $(\mathrm{pH}$ 8.4). The potential was stepwise increased with $1 \mathrm{~V}$ increment.

of $\mathrm{HPO}_{4}{ }^{2-}, \mathrm{H}_{2} \mathrm{PO}_{4}{ }^{-}, \mathrm{H}_{3} \mathrm{PO}_{4}$ and in the case of barrier films on $\mathrm{Al}$, phosphorous species are generally incorporated into $\sim 0.7-0.8$ thickness of the outer barrier layer and moves inward at a rate of $\sim 0.51$ times that of oxygen. ${ }^{45-47}$ Due to the ultra-thin films $(\sim 10-15 \mathrm{~nm})$ grown at $10 \mathrm{~V}$, the detection of any phosphorous species in the anodic film is extremely challenging. Surface-sensitive Raman spectroscopy analysis performed in a separate study on AlHo alloys did not indicate the presence of a phosphate band between $950-1175 \mathrm{~cm}^{-1}$. Similar anodizing response in different electrolytes (Fig. 11a) supports the intrinsic oxidation from Ho thin film surface. Moreover, the polarization curves (Fig. 11a) in borate or phosphate (either alone or in combination with citrate and ethylene glycol) are in complete agreement with our thermodynamic explanation, while the anodizing in citrate discloses the scattered current transients over a range of $\mathrm{pH}$ (Fig. 11b). This further supports our thermodynamic description on Ho(cit) solubility, which predicted the growth of an unstable anodic film on Ho surface. It is now obvious from these experimental observations and thermodynamic simulations that suitable electrolytes for Ho anodizing are those which either do not affect the passivity domain of Ho (such as borate in the case of hydroxide formation or can extend the stability domains to a wider $\mathrm{pH}$ range by impeding the migration of $\mathrm{Ho}^{3+}$ into the electrolyte and by the formation of more stable compound.

Electrochemical impedance spectroscopy.-As described in the introductory remarks, thin films of REE's are of great technological importance. For the purpose of exploring the possible differences in the dielectric properties of the anodic films grown in different electrolytes, simultaneous polarization scans, and EIS measurements were performed by using SDCM. The SDCM allows to completely describe the electrochemical response of a given surface in a small area defined by the wetting surface of the droplet. The details of SDCM as well as sequential CV-EIS study can be found elsewhere. ${ }^{48-50}$ Following each $1 \mathrm{~V}$ potential sweep increment step in CV, EIS was performed for each applied potential up to a maximum of $10 \mathrm{~V}$ vs. SHE.

Dielectric properties of the films can be affected by the localized corrosion associated with the time necessary for EIS measurements. 

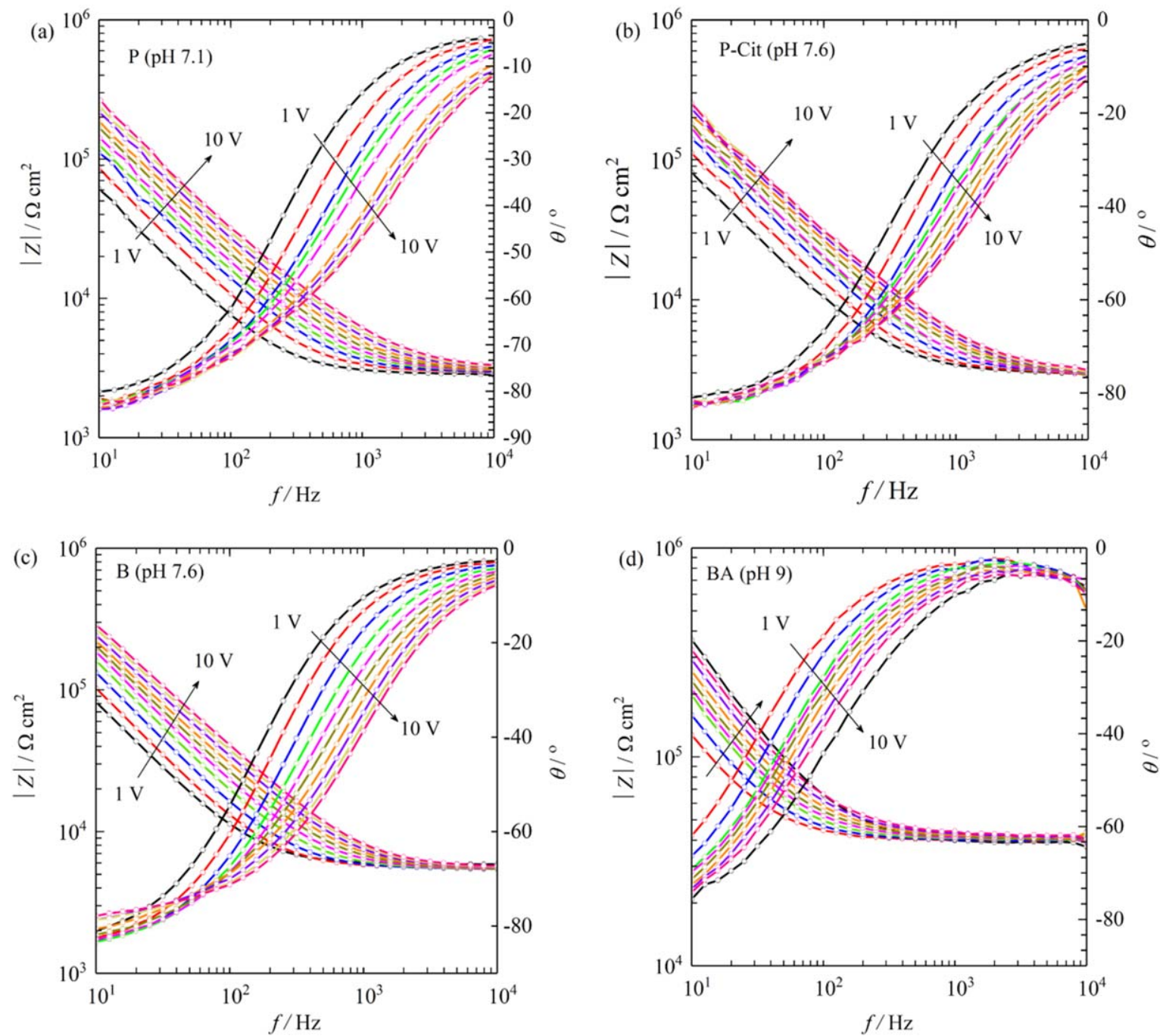

Figure 13. Bode plots during simultaneous $\mathrm{CV}$ and EIS measurements along the thermally evaporated Ho in (a) $0.2 \mathrm{M}$ phosphate buffer (pH 7.1 ), (b) $0.2 \mathrm{M}$ phosphate-0.1 M citrate buffer ( $\mathrm{pH} 7.6$ ), (c) $0.1 \mathrm{M}$ ammonium pentaborate tetrahydrate ( $\mathrm{pH} 7.6$ ), and $0.1 \mathrm{M}$ borate buffer ( $\mathrm{pH} 9.0$ ). The data were recorded after each $1 \mathrm{~V}$ incremental in $\mathrm{CV}$ to a maximum of $10 \mathrm{~V}$.
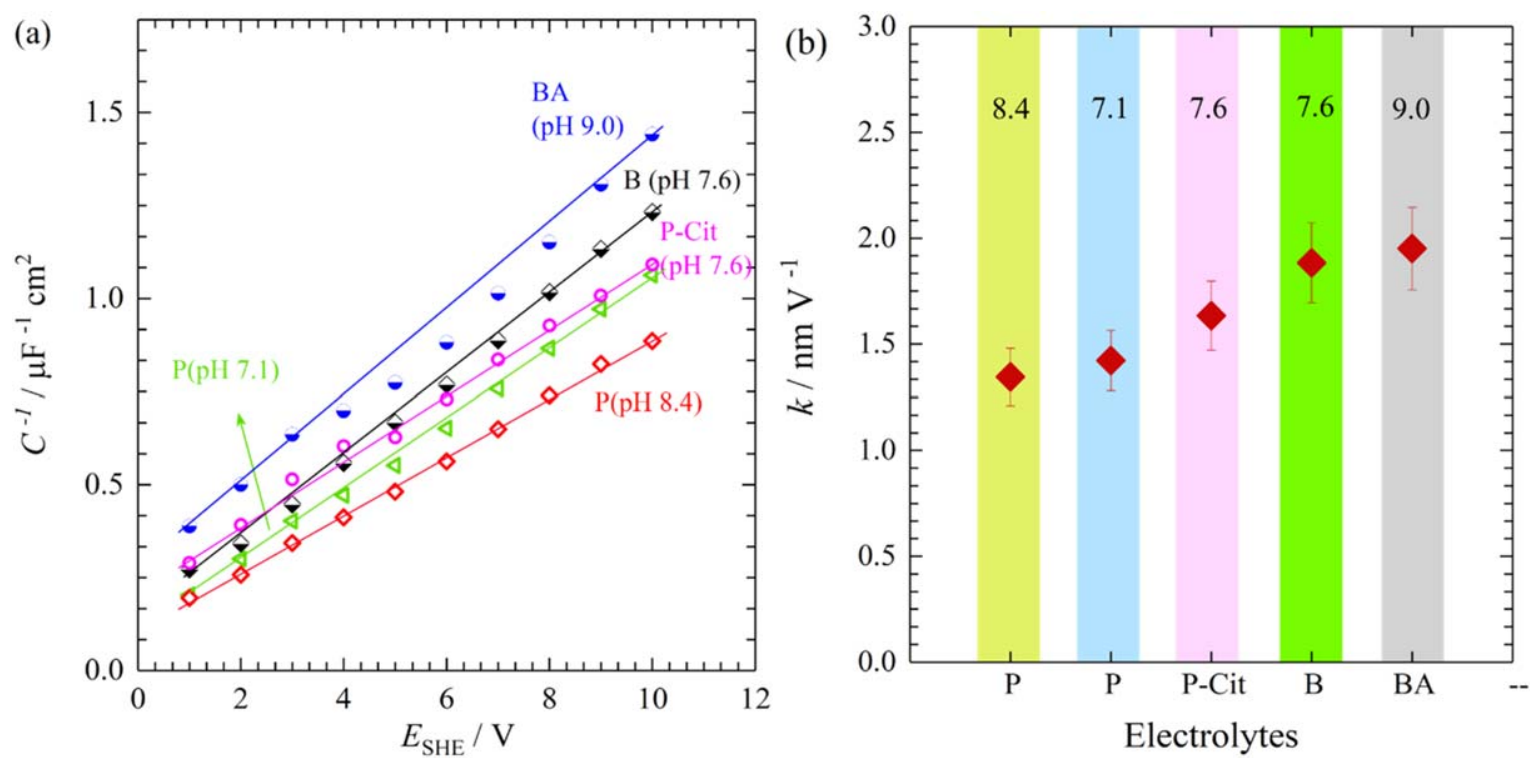

Figure 14. Summary of EIS analysis in the form of (a) reciprocal capacitance $\mathrm{C}^{-1}$ as a function of anodizing potential and (b) film formation factor, $k$ obtained after simultaneous CV-EIS measurements to $10 \mathrm{~V}$ at a sweep rate of $100 \mathrm{mV} \mathrm{s}^{-1}$ in electrolytes having different $\mathrm{pH}$. 


\begin{abstract}
Table III. Relative permittivity, $\varepsilon_{r}$ calculated for Ho in different electrolytes. Relative permittivity estimated for $\mathrm{Al}$ is also shown for comparison.
\end{abstract}

\begin{tabular}{lcc} 
Electrolyte & $\mathrm{k}\left(\mathrm{nm} \mathrm{V}^{-1}\right)$ & $\varepsilon_{\mathrm{r}}=\mathrm{k} / \varepsilon_{\mathrm{o}} \mathrm{m}$ \\
\hline $\mathrm{P}(\mathrm{pH} \mathrm{8.4)}$ & 1.16 & 16.7 \\
$\mathrm{P}(\mathrm{pH} \mathrm{7.1)}$ & 1.36 & 16.1 \\
$\mathrm{~B}(\mathrm{pH} \mathrm{7.6)}$ & 1.53 & 15.7 \\
$\mathrm{BA}(\mathrm{pH} \mathrm{9.0)}$ & 1.95 & 19.4 \\
P-Cit (pH 7.6) & 1.53 & 20.8 \\
Pure Al (pH 8.4) & 1.26 & 10.1
\end{tabular}

Bojinov ${ }^{51}$ proposed the surface charge approach by stating that dielectric properties of oxide films are dominating the impedance response at high- frequency. Therefore, EIS data for most of the electrolytes used in the present study is taken in a high- frequency regime $\left(10^{4}\right.$ to $\left.10^{1} \mathrm{~Hz}\right)$ to avoid any possible chemical/electrochemical dissolution of the film material during the AC perturbation. Figures 12a, 12b, 13d show the CV-EIS results obtained from electrolytes representing two extremes of current transients upon anodizing. The reproducible voltammograms in Figs. 11a, 12a defy any possible chemical/electrochemical dissolution of growing film material during sequential CV-EIS studies, indicating that EIS response actually arises from the anodic film even in a wide frequency scan (Fig. 12b).

Complex Bode plots in Figs. 12b, 13 show the linear changes in the impedance values as a function of frequency at a negative slope and with a phase shift that approaches a value close to $-85^{\circ}$ in the frequency range of $10^{5}$ to $10^{-1} \mathrm{~Hz}$ for $0.2 \mathrm{M}$ phosphate buffer $(\mathrm{pH}$ 8.4). In the narrow frequency range of $10^{4}$ to $10^{1} \mathrm{~Hz}$, the phase shift reaches only $-80^{\circ}$ (Fig. 13), indicating a non- ideal capacitive response from the anodic films. Under such situations, the use of CPE for a suitable simulation of impedance spectra is well established. The impedance associated with CPE can be calculated using the following equation:

$$
\mathrm{Z}_{\mathrm{CPE}}=\frac{1}{\mathrm{Q}(\mathrm{j} \omega)^{\alpha}}
$$

where CPE parameter $Q$ depends on frequency, while the $\alpha$ is independent of frequency. When $\alpha=1$, Q symbolizes capacitance and $\alpha<1$ is generally associated with surface heterogeneity or to distributed time constants. B. Hirschorn et al. pointed out the importance of using a correct formulation for estimating the effective capacitance from constant phase elements and proposed two different approaches for calculating the film capacitance from CPE, based on surface (2D) and normal distribution (3D) of time constant. ${ }^{44}$ Surface distributions result from the distribution of current and/or potential along the surface of the electrode, while a normal distribution arises from surface roughness as well as from different compositions of film material normal to the surface. ${ }^{44,52}$ The derivation of the surface model approach supported the equation presented by Brug et al. ${ }^{53}$ for blocking electrodes and can be ruled out for the present scenario, while the normal distribution provides the formulation akin to Hsu and Mansfeld model. ${ }^{54}$ B. Hirschorn et al. further addressed the consequences of incorrect formula in the calculation of effective capacitance, which will eventually lead to the significantly larger value of film thickness and dielectric permittivity. ${ }^{44}$ In the present case, there is a possibility that anodizing in different electrolytes may lead to the formation of an anodic film contaminated with electrolyte species. ${ }^{55}$ Therefore, in the present study, we adopted the 3D distribution approach for the estimation of capacitance from CPE by using the following HsuMansfeld equation:

$$
\mathrm{C}_{\mathrm{ox}}=\mathrm{Q}\left(\omega_{\max }\right)^{\alpha-1}
$$

in which $R_{f}$ is the film resistance, $\omega_{\max }$ is the angular frequency corresponding to maximum $-Z_{\text {img }}$.

The complete summary of EIS analysis is shown in Fig. 14 in the form of inverse capacitance and formation factor, $k$. It is important to emphasize that regardless of the electrolyte used, a linear relationship between inverse capacitance and the formation voltage is directly observed (Fig. 14a). It is not surprising that electrolytes showing the lower magnitude of current density or low oxygen gas evolution upon anodizing, such as borates, display higher thickness and inverse capacitance values. The film formation factor, $k$ for various electrolytes is calculated from the oxide formation potential, $V$ and thickness, $d$ estimated from EIS analysis (Fig. 14b). The $k$-factor values d were greater than unity irrespective of the electrolyte type, their ionic resistance, and $\mathrm{pH}$ values. It is noteworthy that electrolytes showing different current transients and electrochemical dynamics are still suitable for uniform anodic films. The $k$-factor value of barrier-type films on $\mathrm{Al}$ falls in the range calculated from $\mathrm{Ho}$ anodizing. Thus, similar to anodic alumina, it is inferred that such identical $k$-values, greater than unity, may be responsible for the growth of anodic films on Ho over a wide range of $\mathrm{pH}$.

Finally, the dielectric constant or relative permittivity of films was determined from the slopes of inverse capacitance vs formation potential information. The equation for the determination of dielectric constant of anodic oxides can be derived directly from:

$$
\mathrm{C}^{-1}=\frac{1}{\mathrm{~A} \varepsilon_{\mathrm{r}} \varepsilon_{\mathrm{o}}}\left(d+\mathrm{d}_{\mathrm{o}}\right)=\frac{\mathrm{k}}{\mathrm{A} \varepsilon_{\mathrm{r}} \varepsilon_{\mathrm{o}}} \mathrm{V}+\frac{\mathrm{d}_{\mathrm{o}}}{\mathrm{A} \varepsilon_{\mathrm{r}} \varepsilon_{\mathrm{o}}}
$$

in which $d o$ is the thickness of the natural oxide prior to anodizing, $k$ is the oxide formation factor, $V$ is the formation potential and $\varepsilon_{o}$ and $\varepsilon_{r}$ are the permittivities of free space $\left(8.85410^{-14} \mathrm{~F} \mathrm{~cm}^{-1}\right)$ and oxide, respectively. The above relation indicates that the slope of inverse capacitance vs potential plot would result in the estimation of the dielectric constant of film materials in different electrolytes as summarized in Table III. The value estimated for pure $\mathrm{Al}$ in phosphate buffer electrolyte $(\mathrm{pH} \mathrm{8.4)}$ is shown as a reference. The dielectric constant values for anodic films on Ho range from $\sim 16-20$ and are somewhat higher than the values reported by D. Xue et al. for binary rare earth oxides $\left(\varepsilon_{r}\right.$ for $\left.\mathrm{Ho}_{2} \mathrm{O}_{3}=13.1\right) .{ }^{56}$ The present method of calculating permittivity gives a value of 10.1 which is close to the value reported by many researchers for bulk and thinfilms on Al. The different values of dielectric constants further illustrate the significance of anodizing electrolyte selection for modification the film properties.

In summary, a good correlation between the thermodynamic explanation and experimental observations of film behavior on $\mathrm{Ho}$ has been demonstrated in the present study. The development of Eh-pH diagrams for a given anodizing system is an effective way of understanding the electrochemical response prior to actual experiments. These simulations will not only help in remarkably minimizing the number of attempts to fabricate thin oxide films but will also provide a way to expand the oxidation window by choosing a suitable electrolyte, which subsequently will lead to the modification of film properties for many practical applications.

\section{Conclusions}

In the present work, Eh-pH diagrams are simulated for the systems of $\mathrm{Ho}-\mathrm{H}_{2} \mathrm{O}-$ citrate $(\mathrm{pH}$ 6.0), Ho- $\mathrm{H} 2 \mathrm{O}-$ phosphate-citrate $(\mathrm{pH} 7.6), \mathrm{Ho}-\mathrm{H}_{2} \mathrm{O}-$ phosphate $(\mathrm{pH} 8.4)$, and $\mathrm{Ho}-\mathrm{H}_{2} \mathrm{O}-$-borate $(\mathrm{pH}$ 9.0 ) at $298 \mathrm{~K}$ with the aid of a collection of thermodynamic data to predict the oxidation behaviour of Ho in citrate, phosphate, and borate electrolytes. The method introduced in this paper, i.e. understanding the anodizing behavior with the theoretical development of 
Eh-pH diagrams alongside first-principles calculations in relevant electrolytes has a high potential for efficient formation of anodic films on other rare-earth elements as well as their alloys. The main findings from Eh-pH diagrams are summarized as follows:

- $\mathrm{Ho}-\mathrm{H}_{2} \mathrm{O}$-borate system. The addition of boron containing species does not affect the $\mathrm{Eh}-\mathrm{pH}$ diagrams for hydroxide formation, while the incorporation of $\mathrm{HoBO}_{3}$ species from $\mathrm{Ho}-\mathrm{B}-\mathrm{O}_{2}-\mathrm{H}_{2}$ compositional phase diagram largely extends the stability field of $\mathrm{Ho}-\mathrm{B}-\mathrm{H}_{2} \mathrm{O}$ system, thus promoting film growth at high efficiency.

- $\mathrm{Ho}-\mathrm{H}_{2} \mathrm{O}$-citrate system shows a strong affinity of complex formation leading to unstable anodic film growth.

- $\mathrm{Ho}-\mathrm{H}_{2} \mathrm{O}-$ phosphate-citrate and $\mathrm{Ho}-\mathrm{H}_{2} \mathrm{O}$-phosphate systems show very similar stability regions except for the formation of unstable aqueous $\mathrm{Ho}(\mathrm{cit})$ in $\mathrm{Ho}(\mathrm{OH})_{3}$ stability domain. The introduction of phosphate ions into the aqueous electrolyte enhances the passivity domain of $\mathrm{Ho}$ by the formation of a stable $\mathrm{HoPO}_{4}$. This study clarifies the thermodynamic basis for the anodic oxidation of Ho.

- Cyclic voltammograms reveal that current transients are affected by changing the sweep rate and electrolyte type, while SEM examination and EIS analysis disclose that barrier-type anodic films are developed on Ho with a film formation factor, $k$ greater than unity (1.16 to $1.95 \mathrm{~nm} \mathrm{~V}^{-1}$ ) regardless of electrolytes selection.

- Unlike alumina, the dielectric constants for anodic films on Ho vary from 15.7 to 20.8 in different electrolytes which signifies the crucial role of electrolyte on film properties.

\section{Acknowledgments}

The financial support by the Austrian Federal Ministry of Science, Research and Economy and the National Foundation for Research, Technology and Development through funding of the Christian Doppler Laboratory for Combinatorial Oxide Chemistry (COMBOX) is gratefully acknowledged.

\section{Funding Sources}

Christian Doppler Society through the Christian Doppler Laboratory for Combinatorial Oxide Chemistry (COMBOX).

\section{ORCID}

Jan Philipp Kollender (iD https://orcid.org/0000-0002-9743-9380 Cezarina Cela Mardare (iD https://orcid.org/0000-0001-8930-1560 Andrei Ionut Mardare (D) https://orcid.org/0000-0003-4137-1994

Achim Walter Hassel (iD https://orcid.org/0000-0002-9816-6740

\section{References}

1. A. G. J. Karl (ed.), Industrial Applications of Rare Earth Elements (American Chemical Society, Washington, DC, USA) 164 (1981).

2. S. V. Eliseeva and J. C. G. Bünzli, New J. Chem., 35, 1165 (2011).

3. G. Charalampides, K. I. Vatalis, B. Apostoplos, and B. Ploutarch-Nikolas, Procedia Econ. Financ., 24, 126 (2015).

4. A. Golev, M. Scott, P. D. Erskine, S. H. Ali, and G. R. Ballantyne, Resour. Policy, 41, 52 (2014).

5. A. Jordens, Y. P. Cheng, and K. E. Waters, Miner. Eng., 41, 97 (2013).

6. D. A. Atwood (ed.), "The Rare earth elements." Fundamentals and Applications (Wiley, Lexington, USA), 21 (2012).

7. B. C. McLellan, G. D. Corder, and S. H. Ali, Minerals, 3, 304 (2013).

8. A. A. Khajetoorians and A. J. Heinrich, Science, 352, 296 (2016).

9. K. Kukli et al., Thin Solid Films, 565, 165 (2014).

10. T. Wiktorczyk, IEEE Transactions on Electrical Insulation, 27, 807 (1992).
11. L. B. Lerner and M. D. Tyson, Urol Clin N Am, 36, 485 (2009).

12. A. I. Mardare, C. D. Grill, I. Pötzelberger, T. Etzelstorfer, J. Stangl, and A. W. Hassel, J. Solid State Electrochem., 20, 1673 (2016).

13. M. Pourbaix (ed.), Atlas of Electrochemical Equilibria in Aqueous Solutions (Pergamon Press Ltd., Houston, Texas) (1974).

14. R. L. David, CRC Handbook of Chemistry and Physics (CRC Press, Boca Raton, FL) 90th ed. (2009).

15. A. C. Crossland, G. E. Thompson, P. Skeldon, G. C. Wood, C. J. E. Smith H. Habazaki, and K. Shimizu, Corros. Sci., 40, 871 (1998).

16. A. E. Herrera-Erazo, H. Habazaki, K. Shimizu, P. Skeldon, and G. E. Thompson, Corros. Sci., 42, 1823 (2000).

17. L. Gruss and T. Mackus, J. Electrochem. Soc., 121, 1402 (1974).

18. L. F. Huang, J. R. Scully, and J. M. Rondinelli, Annu. Rev. Mater. Res., 49, 53 (2019).

19. L. F. Huang and J. M. Rondinelli, Phys. Rev. B - Condens. Matter Mater. Phys., 92, 245126 (2015).

20. D. G. Brookins, Geochem. J., 17, 223 (1983)

21. D. G. Brookins (ed.), Eh-pH Diagrams for Geochemistry (Springer, Albuquerque, USA) 53, 122 (1989)

22. E. Kim and K. Osseo-Asare, Hydrometallurgy, 113-114, 67 (2012).

23. F. D. Natterer, K. Yang, W. Paul, P. Willke, T. Choi, T. Greber, A. J. Heinrich, and C. P. Lutz, Nature, 543, 226 (2017).

24. S. Han, Phys. B, 164, 17 (1990).

25. K. Shahzad, C. C. Mardare, D. Recktenwald, A. I. Mardare, and A. W. Hassel, Electrochim. Acta, 297, 888 (2019).

26. K. A. Persson, B. Waldwick, P. Lazic, and G. Ceder, Phys. Rev. B - Condens Matter Mater. Phys., 85, 1 (2012).

27. A. K. Singh, L. Zhou, A. Shinde, S. K. Suram, J. H. Montoya, D. Winston, J. M. Gregoire, and K. A. Persson, Chem. Mater., 29, 10159 (2017).

28. A. Jain, G. Hautier, S. P. Ong, C. J. Moore, C. C. Fischer, K. A. Persson, and G. Ceder, Phys. Rev. B - Condens. Matter Mater. Phys., 84, 045115 (2011).

29. F. H. Firsching, J. Chem. Eng. Data, 37, 497 (1992).

30. M. Aykol, S. S. Dwaraknath, W. Sun, and K. A. Persson, Sci. Adv., 4, 1 (2018).

31. B. Li, M. B. Katz, Y. Duan, X. Du, K. Zhang, L. Chen, A. Van Der Ven, G. W. Graham, and X. Pan, J. Chem. Mater., 27, 18 (2015).

32. S. P. Ong, L. Wang, B. Kang, and G. Ceder, J. Chem. Mater., 20, 1798 (2008)

33. C. D. Taylor, P. Lu, J. Saal, G. S. Frankel, and J. R. Scully, Npj Mater. Degrad., 2, 1 (2018).

34. J. P. M. Van Der Meer, R. J. M. Konings, K. Hack, and H. A. Oonk, J. Chem. Mater., 18, 510 (2006).

35. W. Zhang, D. M. Cupid, P. Gotcu, K. Chang, D. Li, Y. Du, and H. Seifert, J. Chem. Mater., 30, 2287 (2018).

36. F. Donati et al., Science, 352, 318 (2016).

37. S. C. Perry, S. M. Gateman, L. I. Stephens, R. Lacasse, R. Schulz, and J. Mauzeroll, J. Electrochem. Soc., 166, C3186 (2019).

38. R. E. Doe, K. A. Persson, Y. S. Meng, and G. Ceder, Chem. Mater., 20, 5274 (2008).

39. M. M. Lohrengel, Mater. Sci. Eng. R Reports, 11, 243 (1993)

40. M. Herranen, J.-O. C. Corros. Sci., 43, 365 (2001).

41. A. Zaffora, F. Di Quarto, H. Habazaki, I. Valov, and M. Santamaria, Faraday Discuss., 213, 165 (2019).

42. J. P. Kollender and A. W. Hassel, ChemElectroChem, 4, 1846 (2017).

43. C. G. Dunn, J. Electrochem. Soc., 115, 219 (1968).

44. B. Hirschorn, M. E. Orazem, B. Tribollet, V. Vivier, I. Frateur, and M. Musiani, Electrochim. Acta, 55, 6218 (2010).

45. J. J. Randall and W. J. Bernard, Electrochim. Acta, 20, 653 (1975)

46. F. Zhou, D. J. LeClere, S. J. Garcia-Vergara, T. Hashimoto, I. S. Molchan H. Habazaki, P. Skeldon, and G. E. Thompson, J. Electrochem. Soc., 157, C437 (2010).

47. H. Takahashi, J. Electrochem. Soc., 135, 1349 (1988).

48. M. M. Lohrengel, A. Moehring, and M. Pilaski, Fresenius J. Anal. Chem., 367, 334 (2000).

49. A. I. Mardare, A. P. Yadav, A. D. Wieck, M. Stratmann, and A. W. Hassel, Sci. Technol. Adv. Mater., 9, 035009 (2008).

50. A. W. Hassel and M. M. Lohrengel, Electrochim. Acta, 42, 3327 (1997).

51. M. Bojinov, J. Solid State Electrochem., 1, 161 (1997).

52. S. P. Harrington and T. M. Devine, J. Electrochem. Soc., 156, C154 (2009).

53. G. J. Brug, A. L. G. van den Eeden, M. Sluyters-Rehbach, and J. H. Sluyters, J. Electroanal. Chem., 176, 275 (1984).

54. C. H. Hsu and F. Mansfeld, Corros. Sci. Sect., 57, 747 (2001).

55. G. C. Wood, P. Skeldon, G. E. Thompson, and K. Shimizu, J. Electrochem. Soc., 74 (1996).

56. D. Xue, K. Betzler, and H. Hesse, J. Phys. Condens. Matter, 12, 3113 (2000). 